\title{
Access to preventive sexual and reproductive health care for women from refugee-like backgrounds: a systematic review
}

\author{
Natasha Davidson ${ }^{1 *}$, Karin Hammarberg ${ }^{1}$, Lorena Romero ${ }^{2}$ and Jane Fisher ${ }^{1}$
}

\begin{abstract}
Background: Globally, the number of forcibly displaced women is growing. Refugee and displaced women have poorer health outcomes compared to migrant and host country populations. Conflict, persecution, violence or natural disasters and under-resourced health systems in their country of origin contribute to displacement experiences of refugee and displaced women. Poor health outcomes are further exacerbated by the migration journey and challenging resettlement in host countries. Preventive sexual and reproductive health (SRH) needs of refugee and displaced women are poorly understood. The aim was to synthesise the evidence about access to preventive SRH care of refugee and displaced women.
\end{abstract}

Methods: A systematic review of qualitative, quantitative and mixed methods studies of women aged 18 to 64 years and health care providers' (HCPs') perspectives on barriers to and enablers of SRH care was undertaken. The search strategy was registered with PROSPERO in advance of the search (ID CRD42020173039). The MEDLINE, PsycINFO, Embase, CINAHL, and Global health databases were searched for peer-reviewed publications published any date up to 30th April 2020. Three authors performed full text screening independently. Publications were reviewed and assessed for quality. Study findings were thematically extracted and reported in a narrative synthesis. Reporting of the review followed the Preferred Reporting Items for Systematic Reviews and Meta-Analyses recommendations.

Results: The search yielded 4083 results, of which 28 papers reporting 28 studies met inclusion criteria. Most related to contraception and cervical or breast cancer screening. Three main themes and ten subthemes relating to SRH care access were identified: interpersonal and patient encounter factors (including knowledge, awareness, perceived need for and use of preventive SRH care; language and communication barriers), health system factors (including HCPs discrimination and lack of quality health resources; financial barriers and unmet need; HCP characteristics; health system navigation) and sociocultural factors and the refugee experience (including family influence; religious and cultural factors).

Conclusions: Implications for clinical practice and policy include giving women the option of seeing women HCPs, increasing the scope of practice for HCPs, ensuring adequate time is available during consultations to listen and

\footnotetext{
*Correspondence: Natasha.davidson@monash.edu

${ }^{1}$ Global and Women's Health, School of Public Health and Preventive

Medicine, Monash University Faculty of Medicine Nursing and Health

Sciences, Melbourne, VIC, Australia

Full list of author information is available at the end of the article
}

(C) The Author(s) 2022. Open Access This article is licensed under a Creative Commons Attribution 4.0 International License, which permits use, sharing, adaptation, distribution and reproduction in any medium or format, as long as you give appropriate credit to the original author(s) and the source, provide a link to the Creative Commons licence, and indicate if changes were made. The images or other third party material in this article are included in the article's Creative Commons licence, unless indicated otherwise in a credit line to the material. If material is not included in the article's Creative Commons licence and your intended use is not permitted by statutory regulation or exceeds the permitted use, you will need to obtain permission directly from the copyright holder. To view a copy of this licence, visit http://creativecommons.org/licenses/by/4.0/. The Creative Commons Public Domain Dedication waiver (http://creativeco mmons.org/publicdomain/zero/1.0/) applies to the data made available in this article, unless otherwise stated in a credit line to the data. 
develop refugee and displaced women's trust and confidence, strengthening education for refugee and displaced women unfamiliar with preventive care and refining HCPs' and interpreters' cultural competency. More research is needed on HCPs' views regarding care for refugee and displaced women.

Keywords: Refugees, Women, Sexual and reproductive health, Health care providers, Access

\section{Background}

Globally, the number of people who are forcibly displaced both within countries and across borders as a result of conflict, persecution, violence or natural disasters has grown by over $50 \%$ in the last 10 years. In 2009 , 43.3 million people were forcibly displaced, increasing to 79.5 million at the end of 2019 [1]. Of those, 45.7 million comprise internally displaced people, 26 million refugees and 4.2 million asylum-seekers [1]. Forcibly displaced people include those who have meet the United Nations criteria for being a refugee [2], those seeking asylum who are not yet granted refugee status and internally displaced people who have fled their region of origin within their country but have not crossed an international border. In general, refugee and displaced people with past and current migration experiences are considered vulnerable members of the community. The experiences and potential vulnerabilities of women and girls differ significantly from those of men and boys. Women are often afforded lower social status than men which places them in a position of dependency to men. Lack of educational opportunities make it more difficult for women to access decision-making positions and safe employment opportunities. At least half the forcibly displaced people are women and girls [3] with many living for protracted periods in refugee camps in poor conditions [4]. We acknowledge the importance of person-first language but in the interests of brevity, throughout this paper we refer to women from refugee-like backgrounds as "refugee and displaced women". This term signifies the context of women's refugee-like backgrounds and experiences. By definition refugee and displaced women have fled their country or region of origin. The refugee experience places these women in situations which create vulnerability.

Pre-migration experiences caused by violence, torture, rape or witnessing the torture or killing of family or friends are associated with poor psychological and physical health outcomes [5]. Postmigration stress also contributes to poor general health, particularly in refugee and displaced women [6]. Most refugee and displaced women have not voluntarily chosen to leave their country of origin, often depart at short notice, have lengthy journeys within their own country or crossing international borders. They may be separated from family members in transit or at the time of resettlement, have reduced social support systems, be survivors of torture and have lost most of their material possessions, wealth and status [7]. Further, access to ongoing, familiar health services is lost [8]. In their systematic review of young women in Africa, Ivanovna and colleagues [9] concluded that access to and availability of sexual and reproductive health $(\mathrm{SRH})$ care is often limited in low-income country humanitarian settings. As a result, refugee and displaced women are at risk of adverse health outcomes such as unintended pregnancy due to a lack of access to contraception $[10,11]$, lack of access to abortion services [12], sexually transmitted infections [13] and sexual and gender-based violence [14].

Universal publicly available access to SRH care has been recognized by the World Health Organisation as a priority in global health [15]. It is also of key importance in Sustainable Development Goal 3 which seeks to ensure good health and wellbeing for all and Sustainable Development Goal 5 which seeks to achieve gender equity [16]. In World Bank classified [17] low-income countries however, women's health services, particularly preventive SRH care including contraception, cervical and breast cancer screening and human papilloma virus (HPV) vaccination is often not available or not of a quality that meets the World Health Organisation framework for human rights standards [18]. A fact further supported at the International Conference on Human Rights in 2013 [19]. Poor quality relates to lack of universal access to SRH care and scarce human and financial resources [20] in addition to lack of patient centred care [21] and respectful, effective and efficient communication [22]. The concept of an Essential Package of Health Services was initiated by World Health Organisation in 2014 to progress universal access to SRH. Its aim was to provide priority health services for vulnerable populations in fragile settings, where needs often exceed available resources [15]. The Essential Package of Health Services across most low- and middle-income countries excludes many SRH services [23]. An analysis based on low- and middleincome countries' health services [20] showed almost all countries included maternal health care and some had SRH care for family planning and sexually transmitted infection/human immunodeficiency virus prevention and management. However, the majority did not mention infertility, or screening for cervical and breast cancers. By contrast, most women in high-income countries have free or low cost universal SRH access in primary health 
care including screening for reproductive cancers [24]. The poor quality of SRH care but also a lack of available services, leads to low utilisation of these services [25] further contributing to barriers refugee and displaced women may experience in accessing care [26]. In 2004, a global evaluation of reproductive health services for refugees and internally displaced people concluded that most people affected by conflict lack adequate SRH care. Refugee and displaced women have been overlooked in humanitarian and in transit low-income country settings and consequently have unmet SRH needs and poor SRH outcomes [27].

Following resettlement refugee and displaced women's use of primary health care is limited. A systematic review by Hadgkiss and Renzaho [28] examining asylum seekers residing in the community in high-income countries found they had higher tertiary level health service use but lower preventive health service use than the host population. Annual hospitalisation rates among asylum seekers in the Netherlands varied from 12 to $20 \%$ compared with $7 \%$ in the general population. With regard to use of preventive health services, $25 \%$ of asylum seekers had undergone a cervical pap screening test compared with $62 \%$ in the host population [28]. Similarly, Sarría-Santamera and her colleagues compared use of health services between populations and found over-use of emergency services and under-use of preventive care services among immigrants and refugees compared to host populations [29].

To date research on refugee and migrant women's access to SRH care has mainly focused on pregnancy, childbirth and post-partum health care [30-35]. Others have focused on people with refugee-like backgrounds experiences in general practice [36,37]. Few systematic reviews on the topic of SRH disaggregate findings pertaining to refugees, internally displaced people and asylum seekers from those of other immigrants [35, 38]. Refugee and displaced women have particular needs when engaging with the SRH care [39].

Primary HCPs are key to ensuring SRH care needs are meet, yet understanding of HCPs' perspectives on refugee and displaced women's access to care is limited. One systematic review of qualitative studies explored challenges and facilitators for HCPs providing general primary healthcare for refugees and asylum seekers in high-income countries [40]. This review identified multiple barriers experienced by HCPs in providing care for refugees and asylum seekers. Factors related to HCPs competency and responsiveness can contribute to the underutilisation of SRH care by refugee and displaced women [41]. Brandenberger and colleagues [38] go one step further and identify the need for comprehensive training of HCPs to understand the specific requirements of migrants and refugees.
There is a gap in the literature that explicitly addresses access to preventive SRH care outside pregnancy and maternal health among refugee, internally displaced and asylum seeker populations. It is not known what the experiences of access to preventive SRH care and provision of care are for refugee and displaced women nor the views of HCPs delivering care to this group. The aim of this review was to synthesize the evidence on barriers to and enablers of access to preventive SRH care from the perspectives of refugee and displaced women and their health care providers.

\section{Methods}

The systematic review was registered with PROSPERO database in advance of the search (ID CRD42020173039). Reporting of the review followed the Preferred Reporting Items for Systematic Reviews and Meta-Analysis recommendations [42].

\section{Selection criteria \\ Inclusion and exclusion criteria}

The inclusion criteria were studies that have been peerreviewed, used qualitative, quantitative or mixed methods and have investigated barriers to or enablers of access to SRH care from the perspective of refugee and displaced women defined as refugees, asylum seekers and internally displaced people; or HCPs' views about providing SRH care to refugee and displaced women in primary health care settings. Exclusion criteria were investigations of maternity or obstetric care (Additional File 1).

\section{Search strategy}

The search strategy was devised by ND with the assistance of a specialist information analyst, LR. The MEDLINE, EMBASE, PsycINFO, CINAHL and GLOBAL HEALTH databases were searched for peer reviewed papers published any date up to 30th April 2020. The search strategy was based on the Sample, Phenomenon of Interest, Design, Evaluation, Research type (SPIDER) tool [43] to optimise identification of relevant articles. The detailed search strategy is documented in Additional file 2.

Search limits included: English language and women aged 18 to 64 years. No date or country of setting limits were applied. The included articles' reference lists were hand-searched for additional relevant articles. Articles identified in the search were exported to EndNote X9. After removal of duplicates the remaining articles were exported to Covidence Systematic Review Management Platform [44]. 


\section{Selection}

Titles and abstracts were screened for relevance by $\mathrm{ND}$ and articles that did not meet inclusion criteria were removed. Full text of the remaining articles were reviewed independently in Covidence [44] by $\mathrm{ND}, \mathrm{KH}$ and JF. Any disagreements were resolved through discussion to come to a final decision.

\section{Data extraction}

Study characteristics were extracted by ND using a preset proforma in Microsoft Excel. Data were extracted on the following key characteristics: author, title, year published, country of study, study aim, theoretical framework, study design, sampling technique, participant characteristics (including age group, country of origin, migration category and time since arrival), sample size, data collection method, data analysis, outcome measures, SRH topic covered, and key findings.

\section{Quality assessment}

Study quality was assessed using the Kmet Standard Quality Assessment Criteria for Evaluating Primary Research framework for appraisal tool [45]. The Kmet tool provides a systematic reproducible and quantitative means of appraising qualitative and quantitative studies. Mixed-methods studies were appraised using both the qualitative and quantitative quality assessment criteria. In addition, for all studies, evidence of human research ethics committee approval was scored 0 for 'no ethics approval' and 1 for 'has ethics approval' approved by a formally constituted ethics committee.

\section{Data synthesis}

Narrative synthesis is a systematic approach to searching for and quality appraising evidence. In systematic reviews it is used to explore relationships within and between study findings. Narrative synthesis is an area of emerging research in the field of systematic reviews, however there are broad guidelines which have been followed to guide this review process [46]. This method was reported because characteristics of the study designs and outcomes were too diverse to yield a meaningful summary of findings using a meta-analysis.

The main findings and conclusions were grouped and coded inductively into descriptive themes that emerged from the data within the two categories of "barriers to" and "enablers of" access to SRH care, as defined by the review aim. Findings were only coded if they related to barriers to or enablers of SRH care. Data were further grouped into the SRH topic. Findings were coded to iteratively develop and refine descriptive themes, with each study able to contribute new themes. Following the organisation of these descriptive themes, categorisation and generation of higher-level analytical themes were devised. Quantitative data were described separately and used to complement or refute the qualitative evidence.

\section{Results}

Systematic database searches yielded 4083 articles. 28 studies were included in the review (Fig. 1).

\section{Study characteristics}

Study characteristics and main findings are shown in Tables 1 and 2.

\section{Study locations}

Of the 28 studies, 13 were conducted in the USA [48, 53, 55-57, 59-61, 63, 69, 72-74], two each in Australia [62, 64], Jordan [52, 68], Lebanon [49, 50] and Canada [70, 71], one each in Congo [66], Israel [54], Netherlands [67], Pakistan [65], South Korea [65], Thailand [47] and one was a multi country study which included Bangladesh, Jordan, Djibouti, Kenya, Malaysia and Uganda [51].

\section{Data collection methods}

Studies were qualitative $(n=16)$, cross sectional surveys $(n=8)$ and mixed methods; a combination of either focus group discussions (FGDs) or semi structured interviews and surveys $(n=4)$. Of those using qualitative methods, nine involved FGDs [49, 50, 53, 55-57, 59-61], four semi structured interviews $[49,52,58,63]$, three indepth/key informant interviews $[47,56,64]$, three both FGDs and in-depth interviews $[48,51,54]$ and one used a novel storytelling method [62]. Of the 12 studies using quantitative methods, nine used face-to-face interview based surveys in respondents' homes $[47,51,65,66$, $68,70,73]$ or in a medical clinic [72] and one used an online survey [57]. The remaining studies used population-based data sources (electronic medical and national immigration record databases) $[67,71]$ and review of medical charts [69].

\section{Study samples}

Twenty-six studies focused on refugees [47-53, 55-65, 67-74], one on asylum seekers [54] and one on internally displaced persons [66]. Five studies included perspectives of HCPs (not further specified) [48, 51, 74] and one each of physicians [54] and nurses [50]. Ethnic groups included Somali /Somali Bantu in seven studies $[48,53,55,56,60,72,73]$, Syrian $[49,50,52]$ and Bhutanese $[57,59,64]$ in three studies each, and one each in Afghani [65], Albanian [70], Burmese [59], Cambodian [47], Congolese [66], Eritrean [54], Iraqi [61], North Korean [58], Palestinian [68], West African [62] or a combination of these ethnic groups $[51,63,67,69$, 71]. Participants' ethnicity was not described in one 


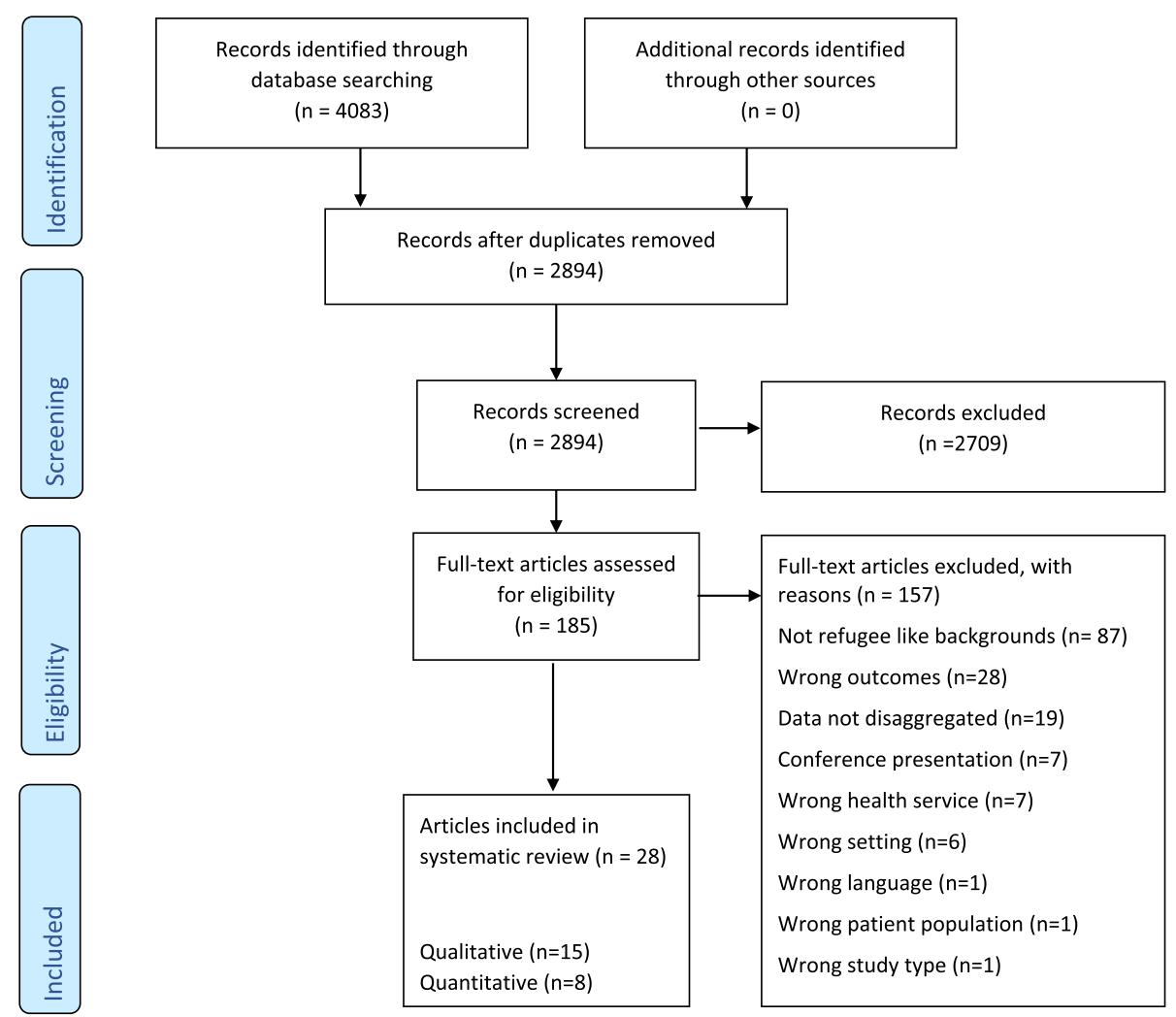

Fig. 1 Flow diagram showing the process of study selection (adapted from [42])

study [74]. Qualitative data were available from 994 participants (samples ranged between 5 and $\sim 65$ ) and quantitative data were available from 469,984 participants (samples ranged between 42 and 455,684).

\section{Recruitment methods}

Recruitment methods were described in all but one qualitative study [51]. They included convenience sampling with $[48,52-55,61-63]$ or without snowball sampling $[49,60]$ through community or health centres, migrant resource centres or places of worship. Purposive sampling was used in studies of refugee and displaced women and HCPs in various primary health care settings $[50,51,56,58,62]$. Several studies engaged community gatekeepers such as community activists, group leaders or women community partners in recruitment of participants $[47,50,54,55,59]$. Of eight quantitative studies, four recruited convenience samples [66, 72-74], two obtained data from random samples of households [65] and families [70] and two employed medical record searching $[67,69]$.

\section{Quality assessment}

The quality of the 28 studies varied considerably with KMET scores ranging between 0.60 and 1.0 for qualitative and 0.50 to 1.0 for quantitative studies. Twenty-two studies reported obtaining ethics approval and six did not. Quality assessment is summarized in Additional files 3 and 4 .

\section{Type of SRH topic examined}

All but two studies included at least one of the three main SRH topics: contraception [47-56, 65-68], cervical cancer screening $[57,58,60,62,71,74]$ or breast screening $[63,64]$ with the remaining three examining a combination of these $[61,69,70]$. One examined access to primary care for women who had experienced female genital cutting of different types [73] and one women's preference for providers of general physical examinations which include breast and pelvic examinations [72].

\section{Thematic extraction of findings}

Table 3 summarises the three main themes and 10 subthemes identified in this review. 


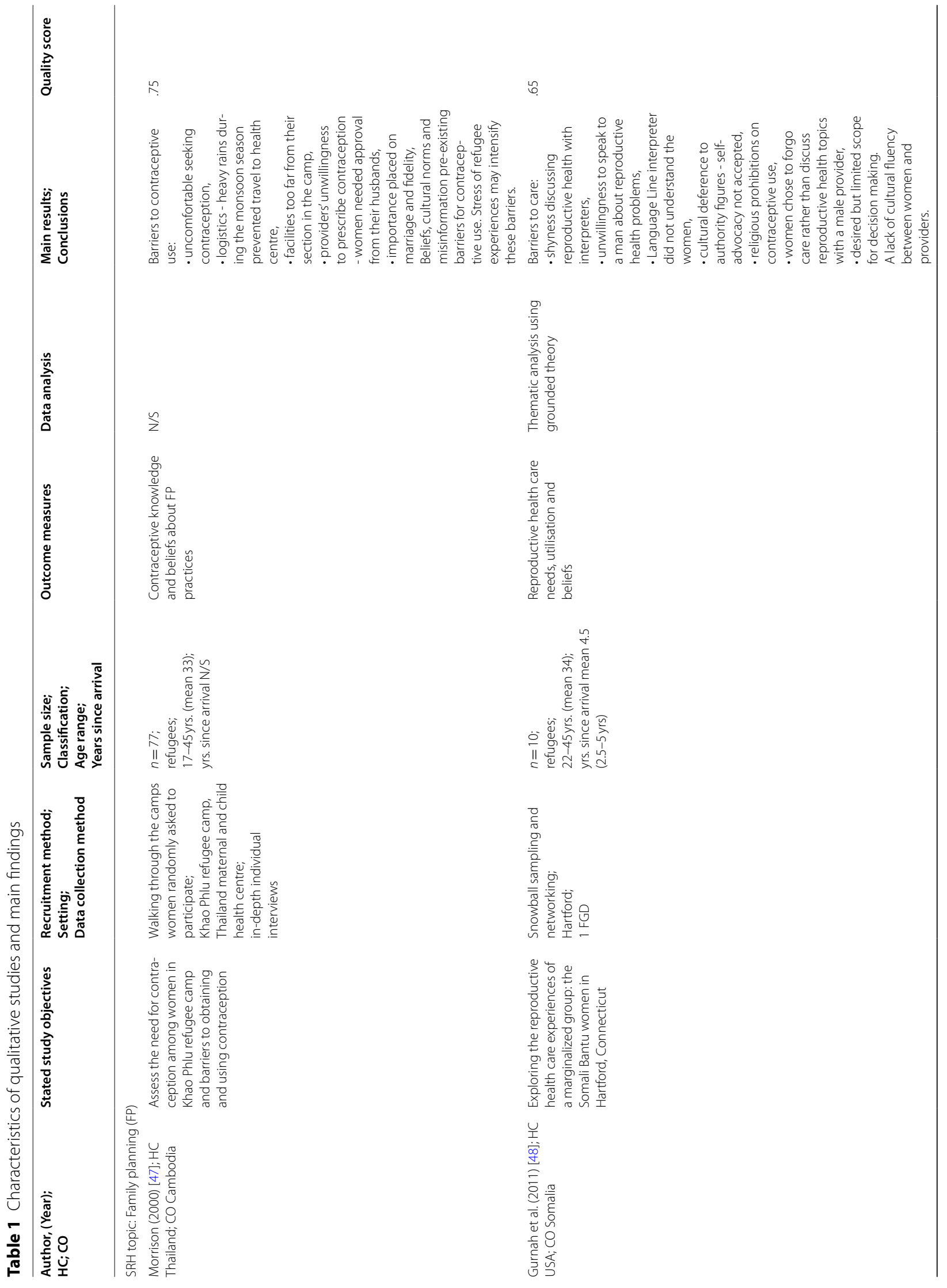




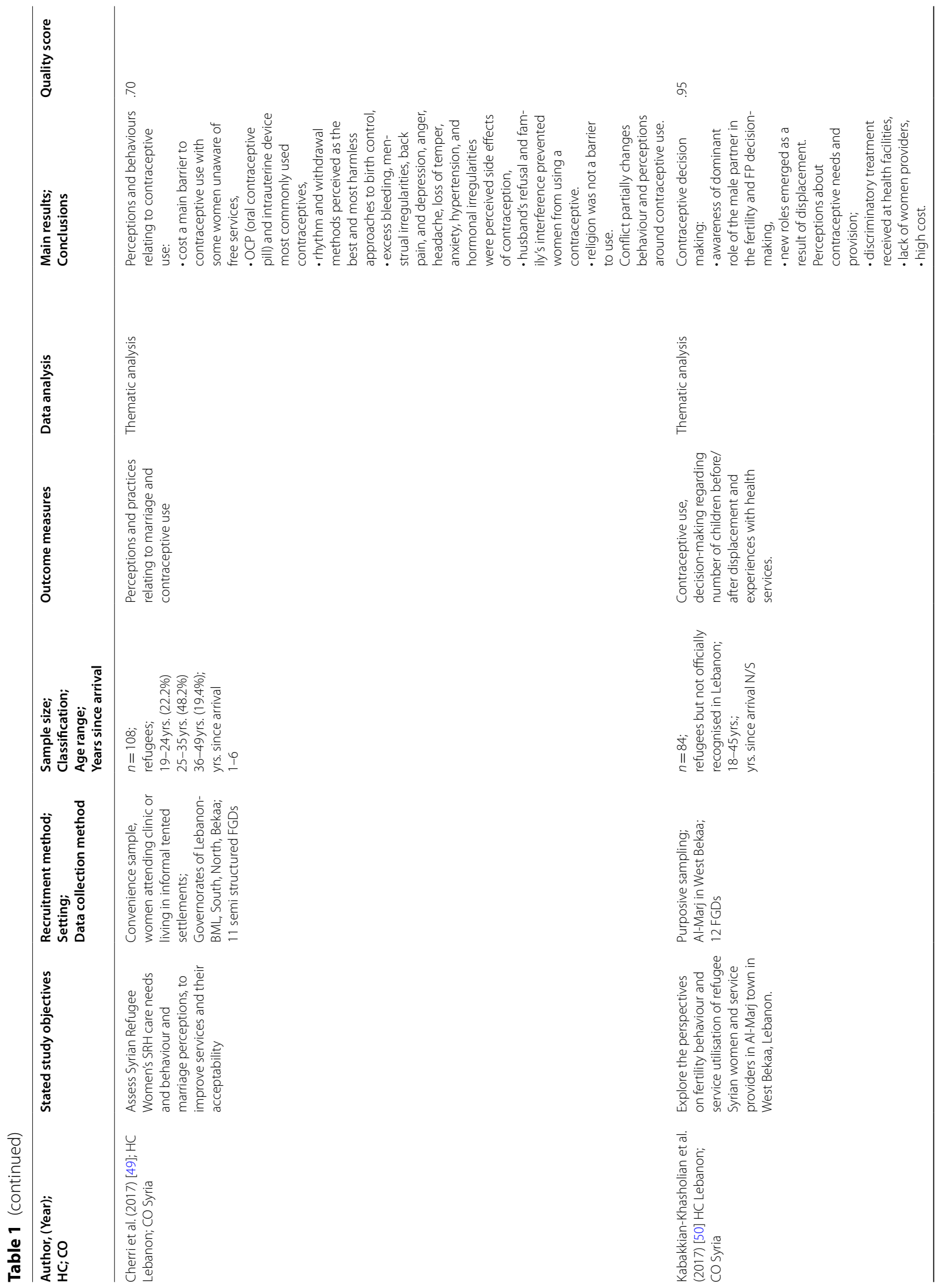




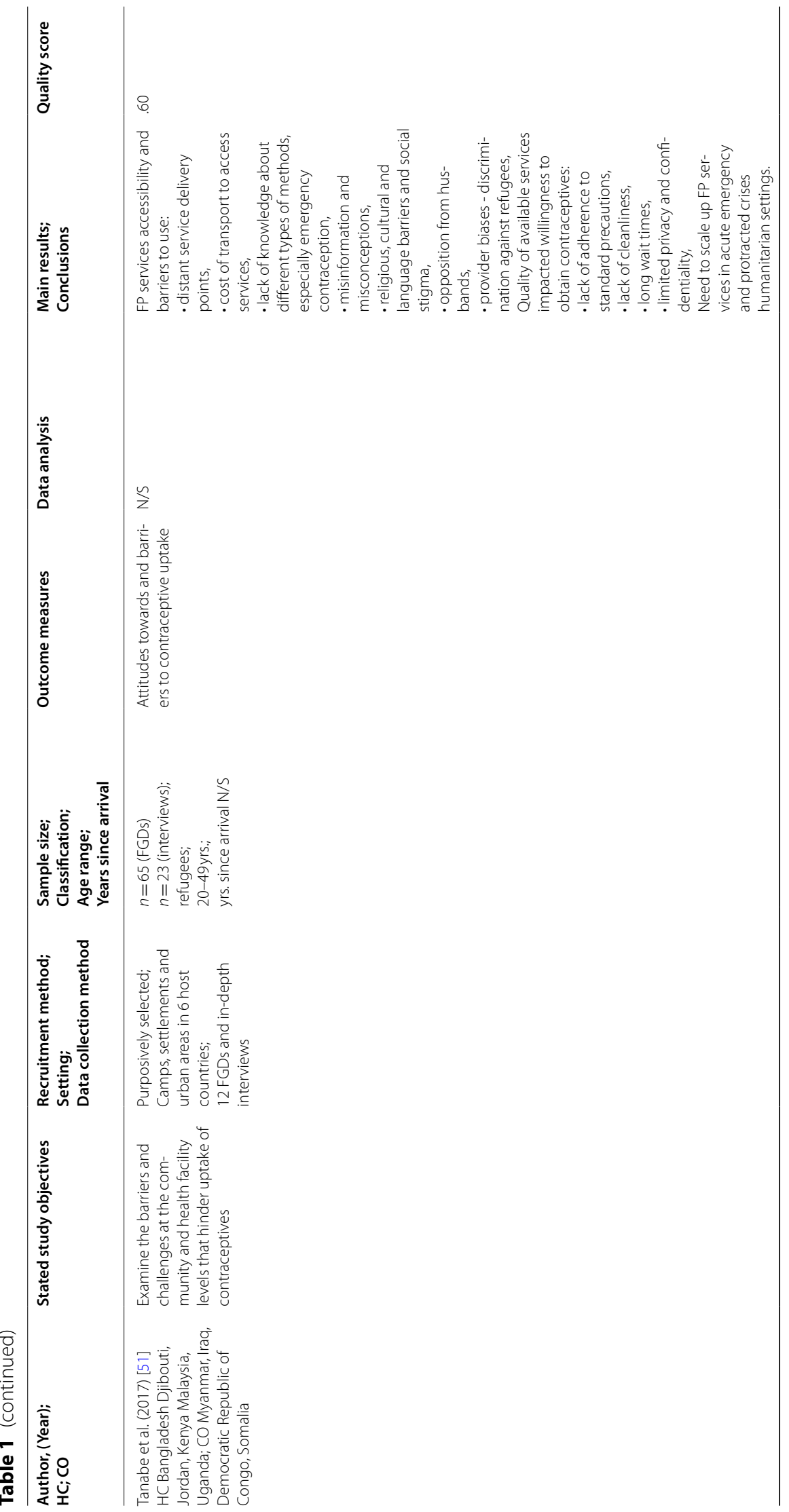









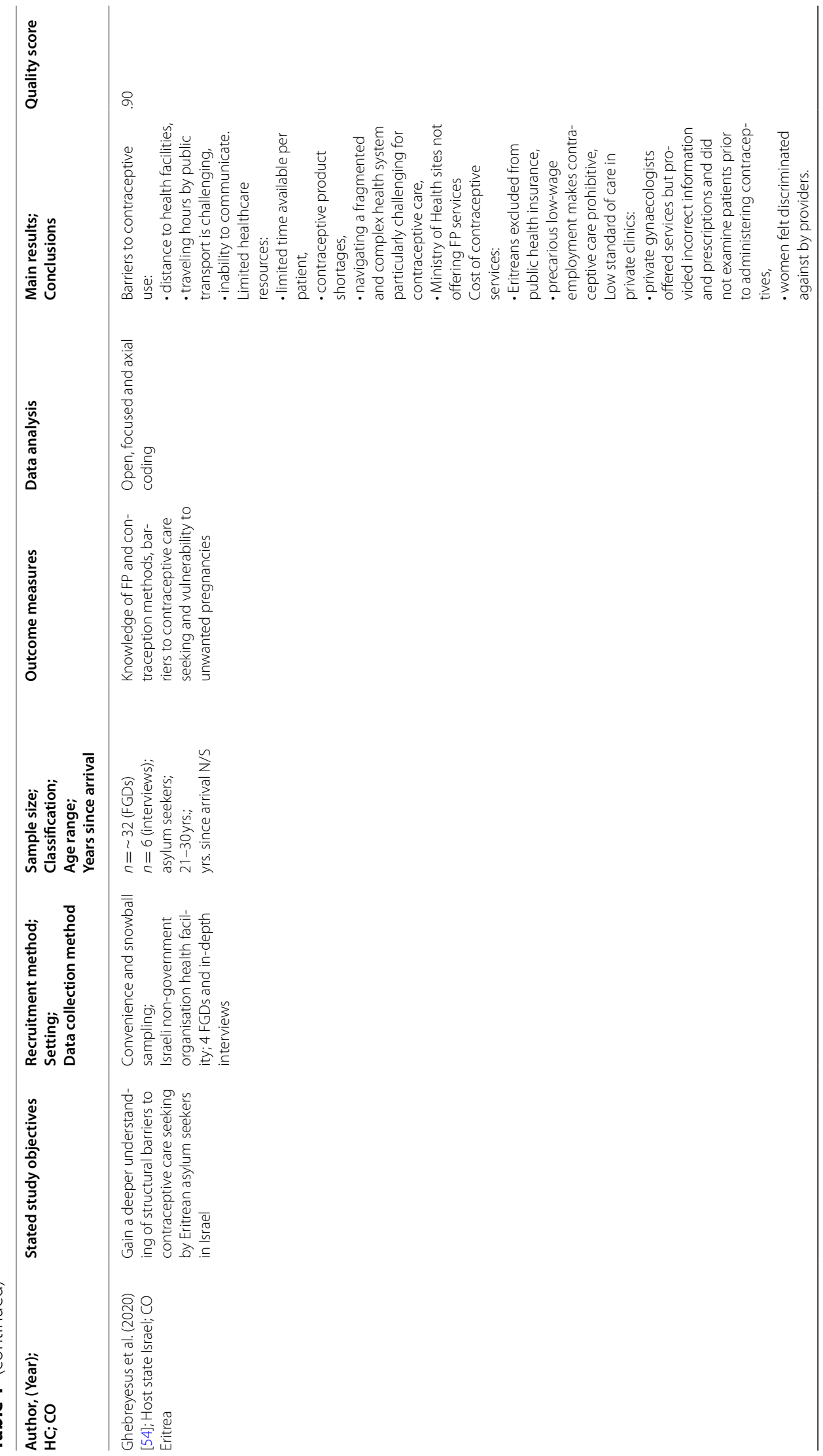




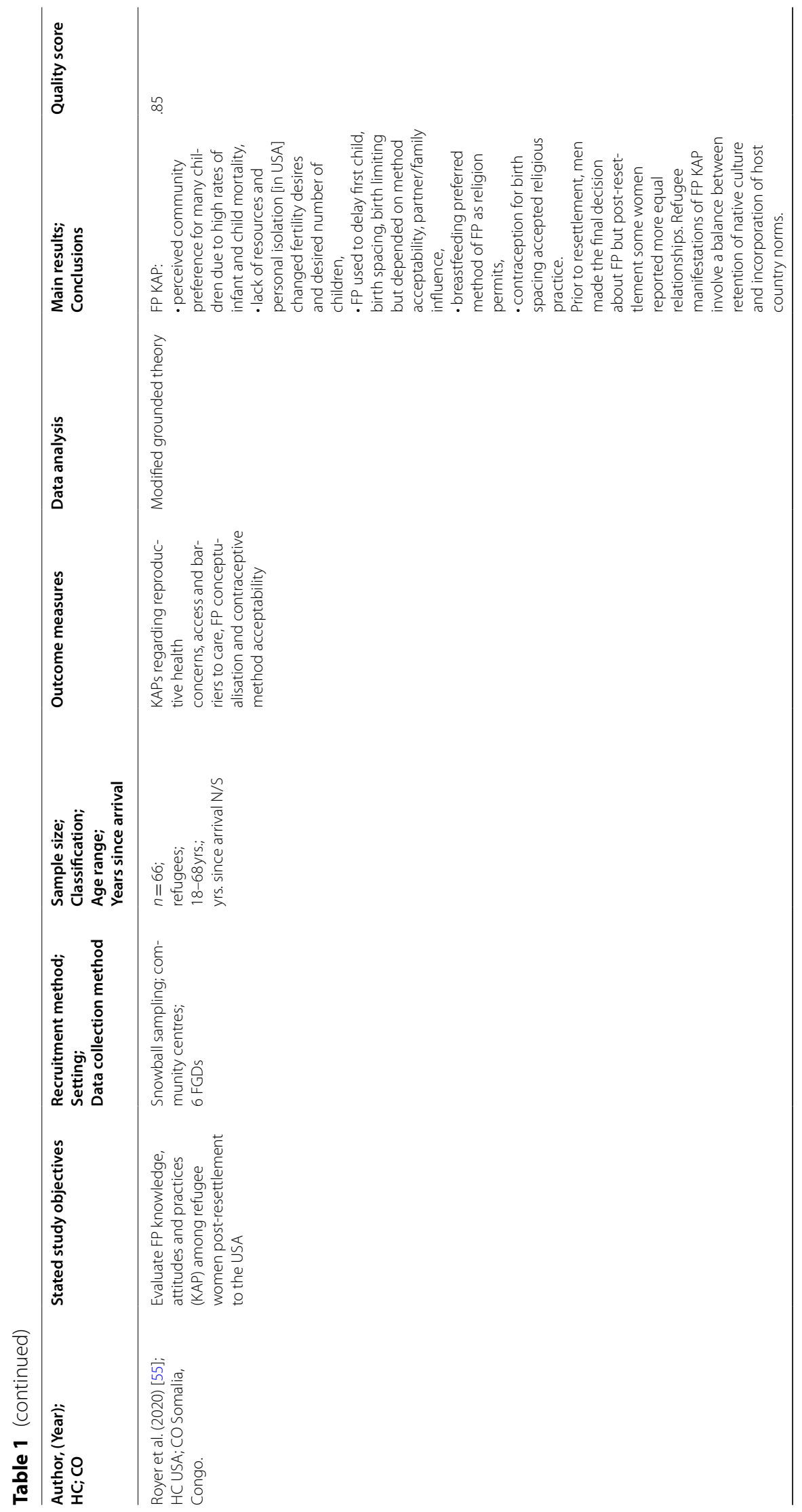




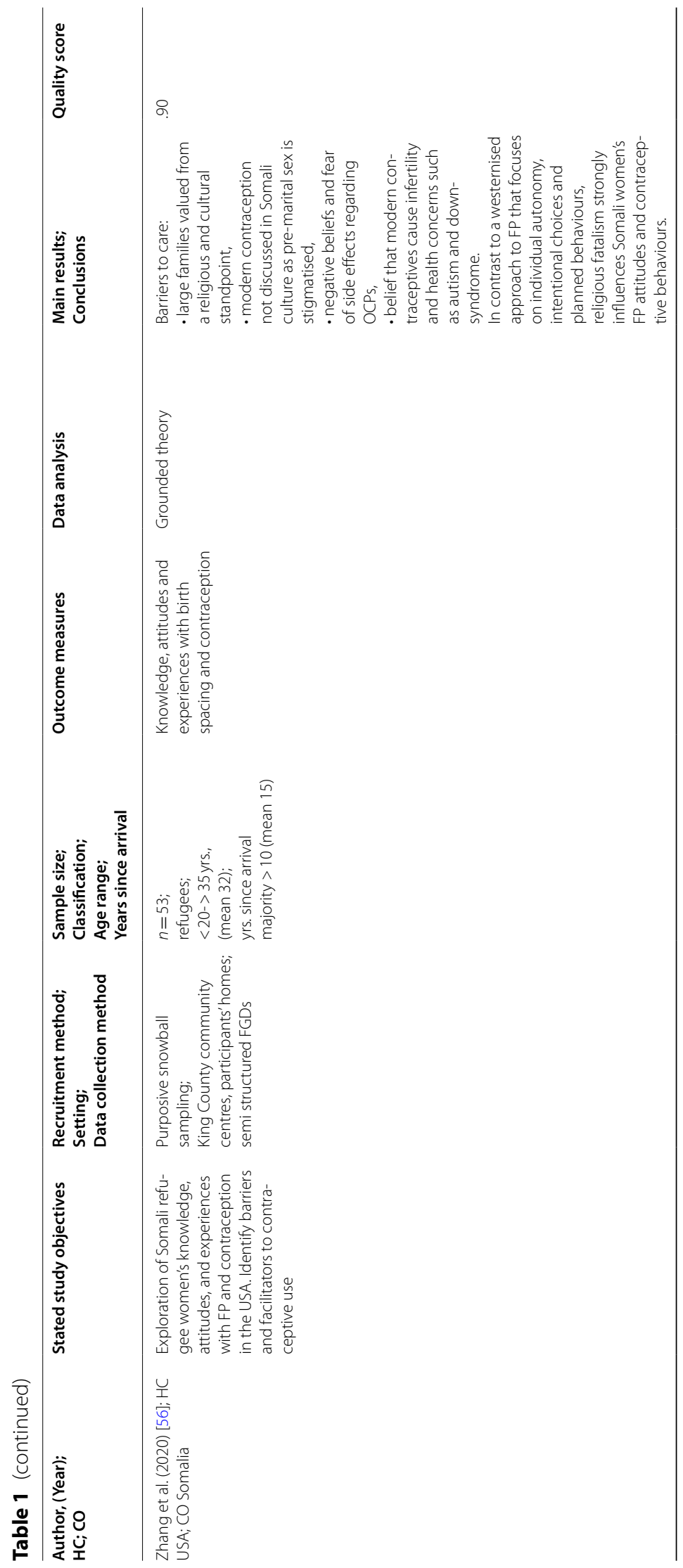




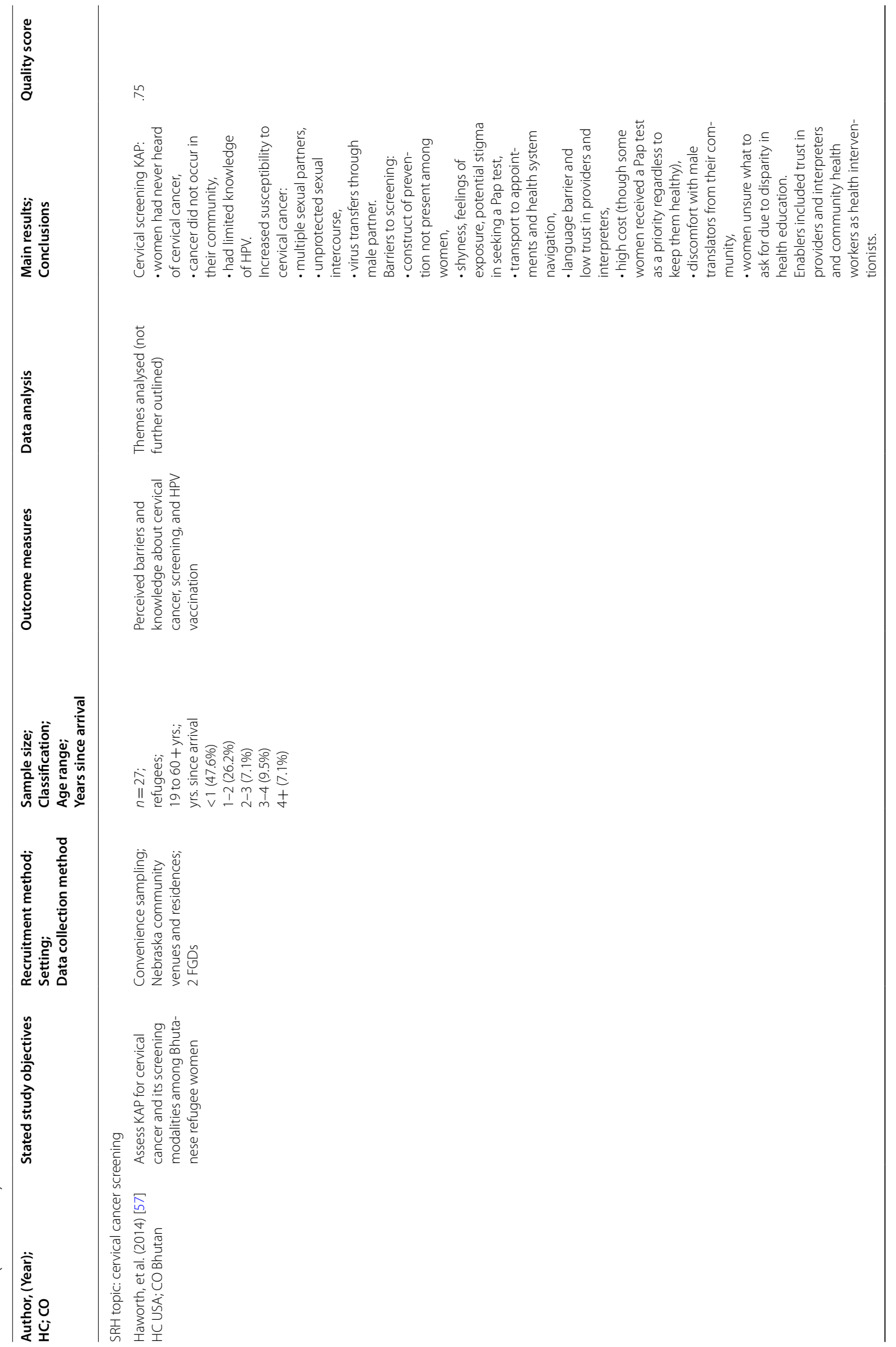




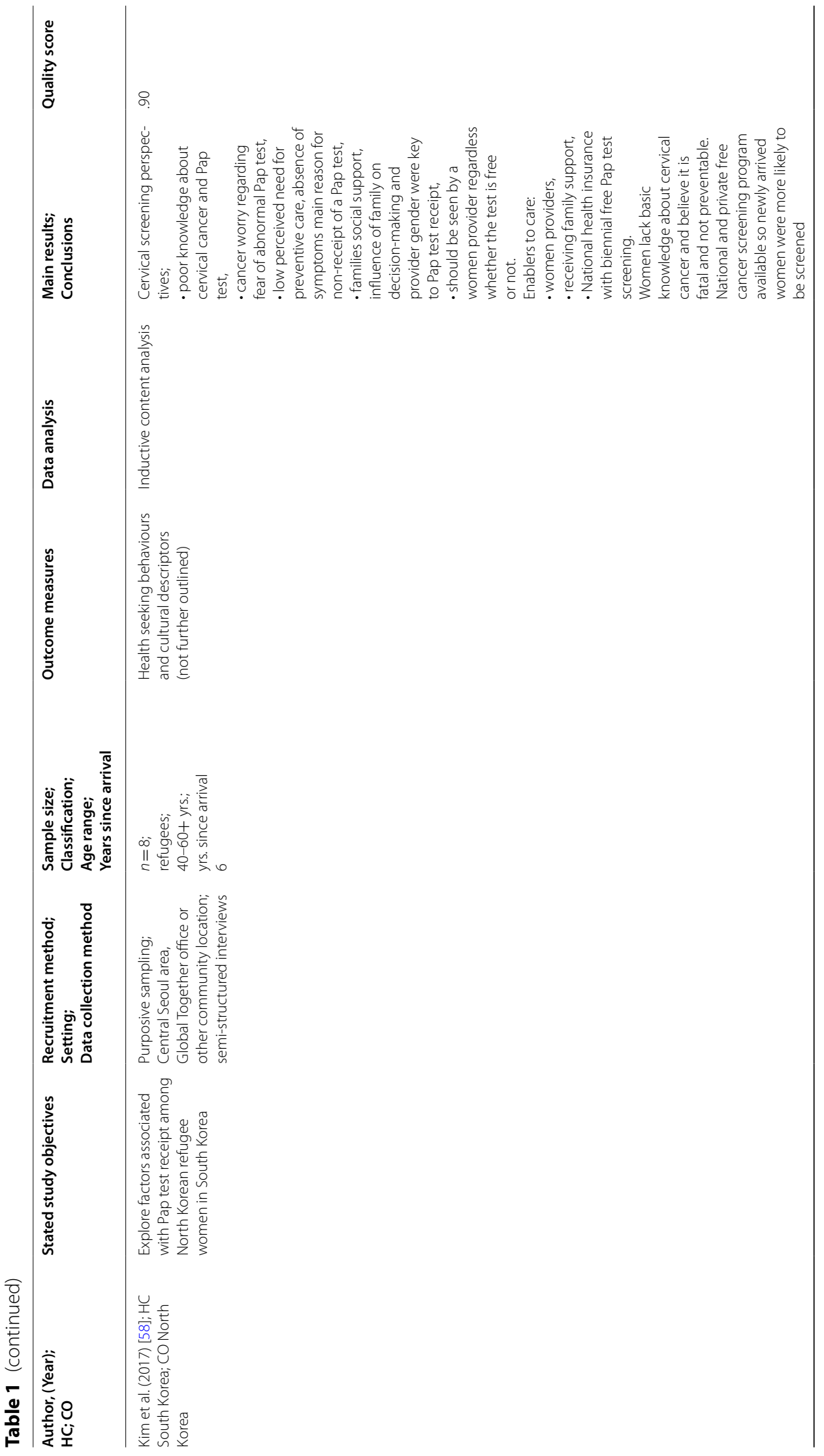




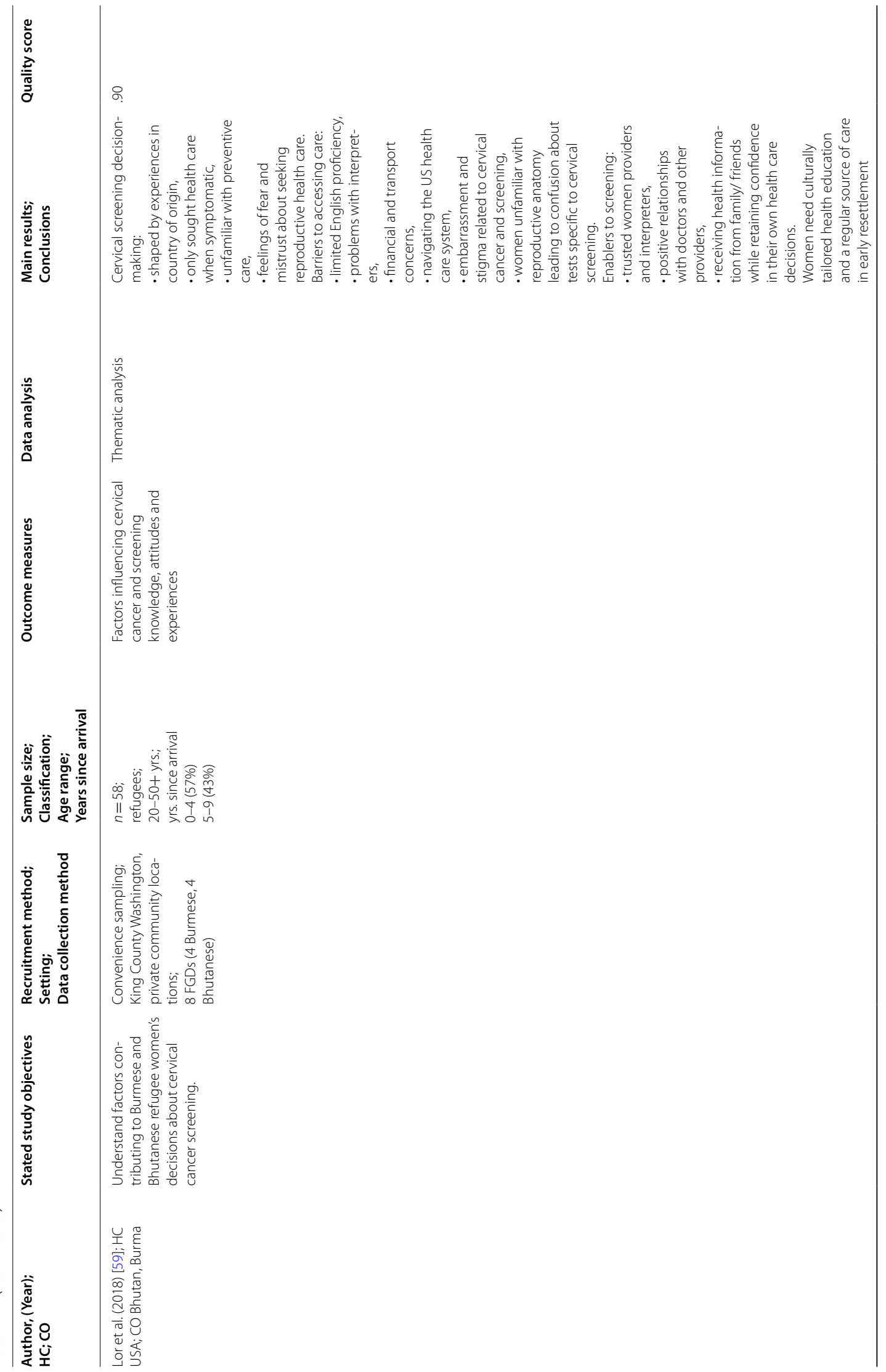




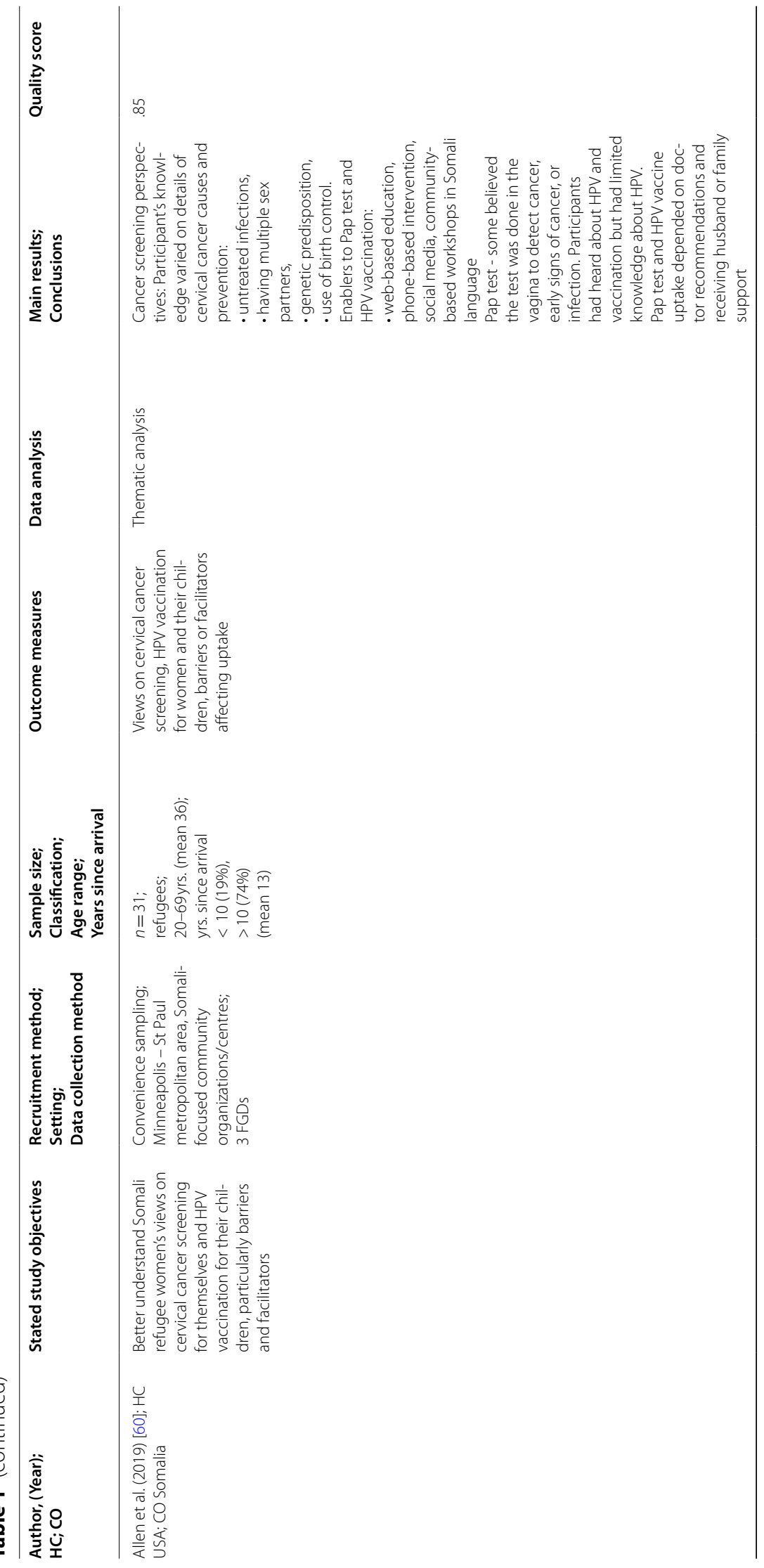




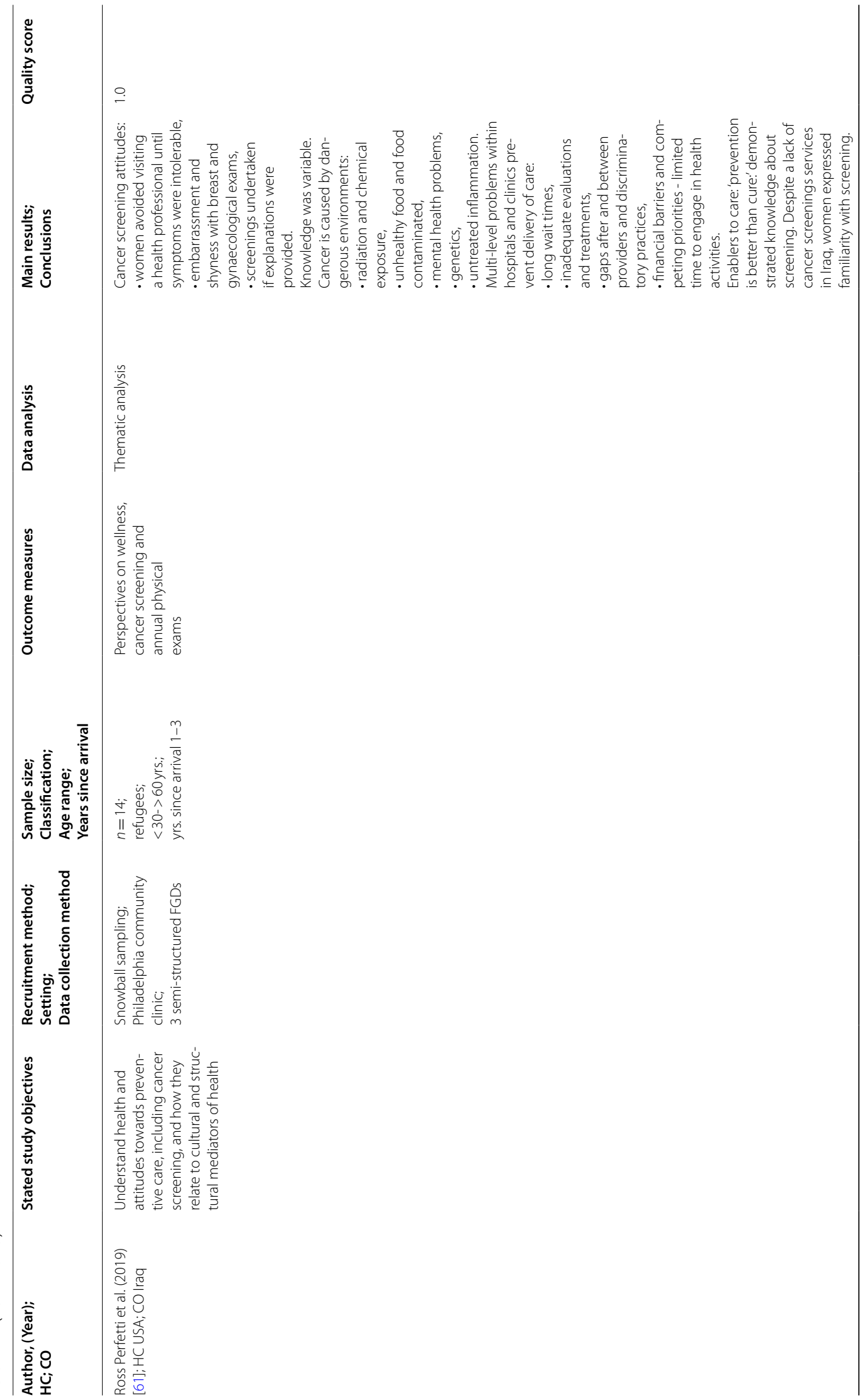




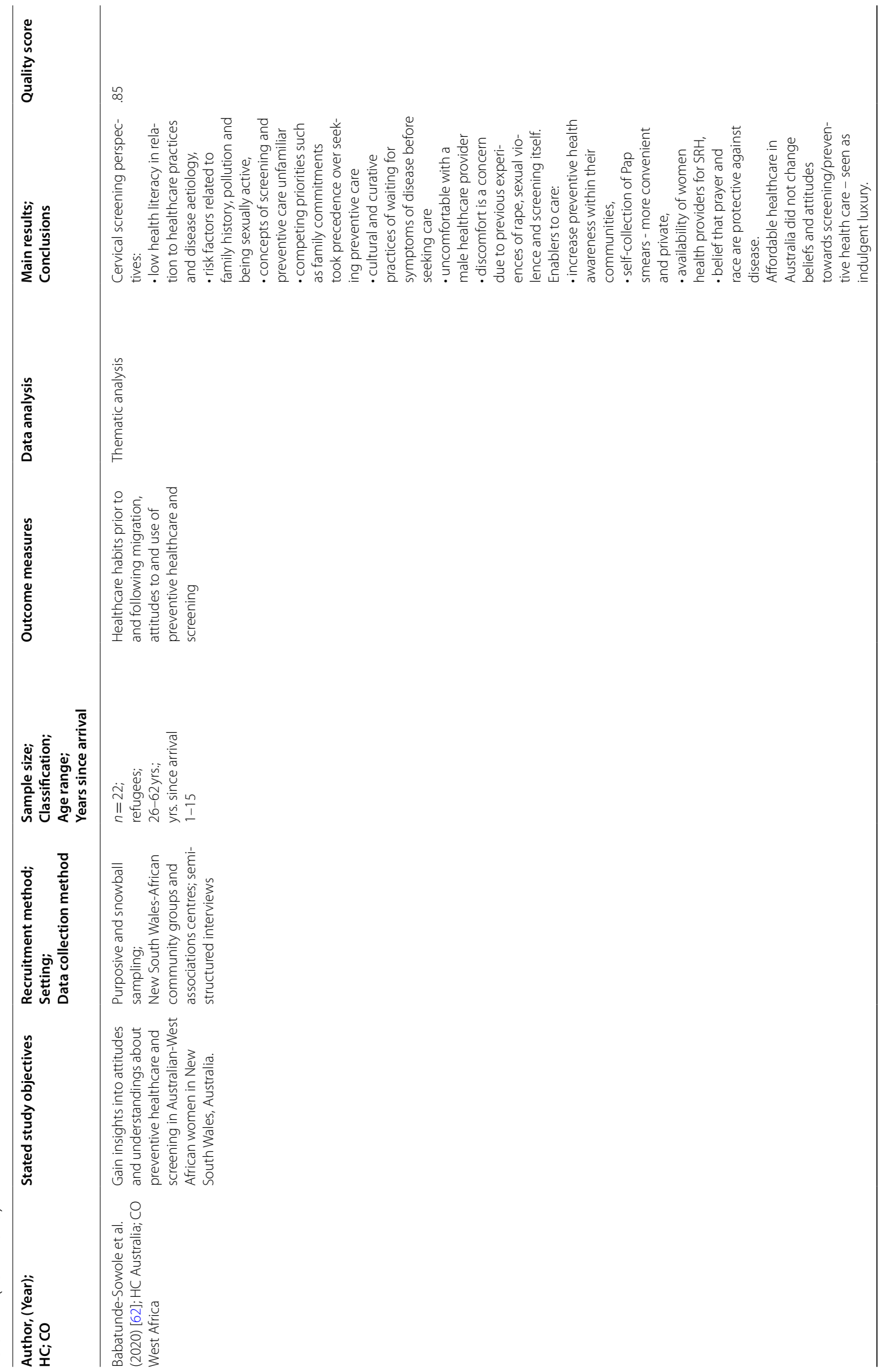




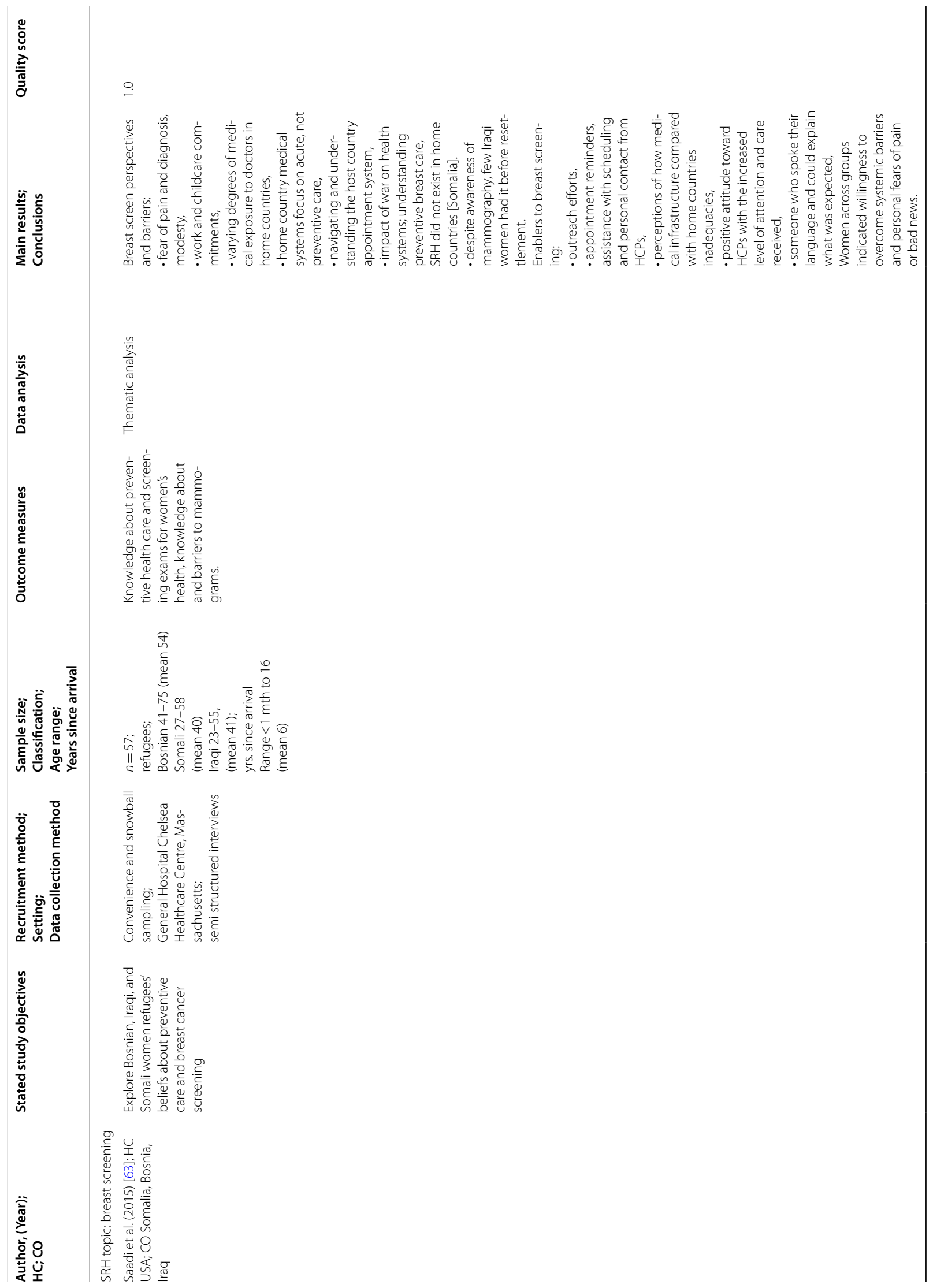




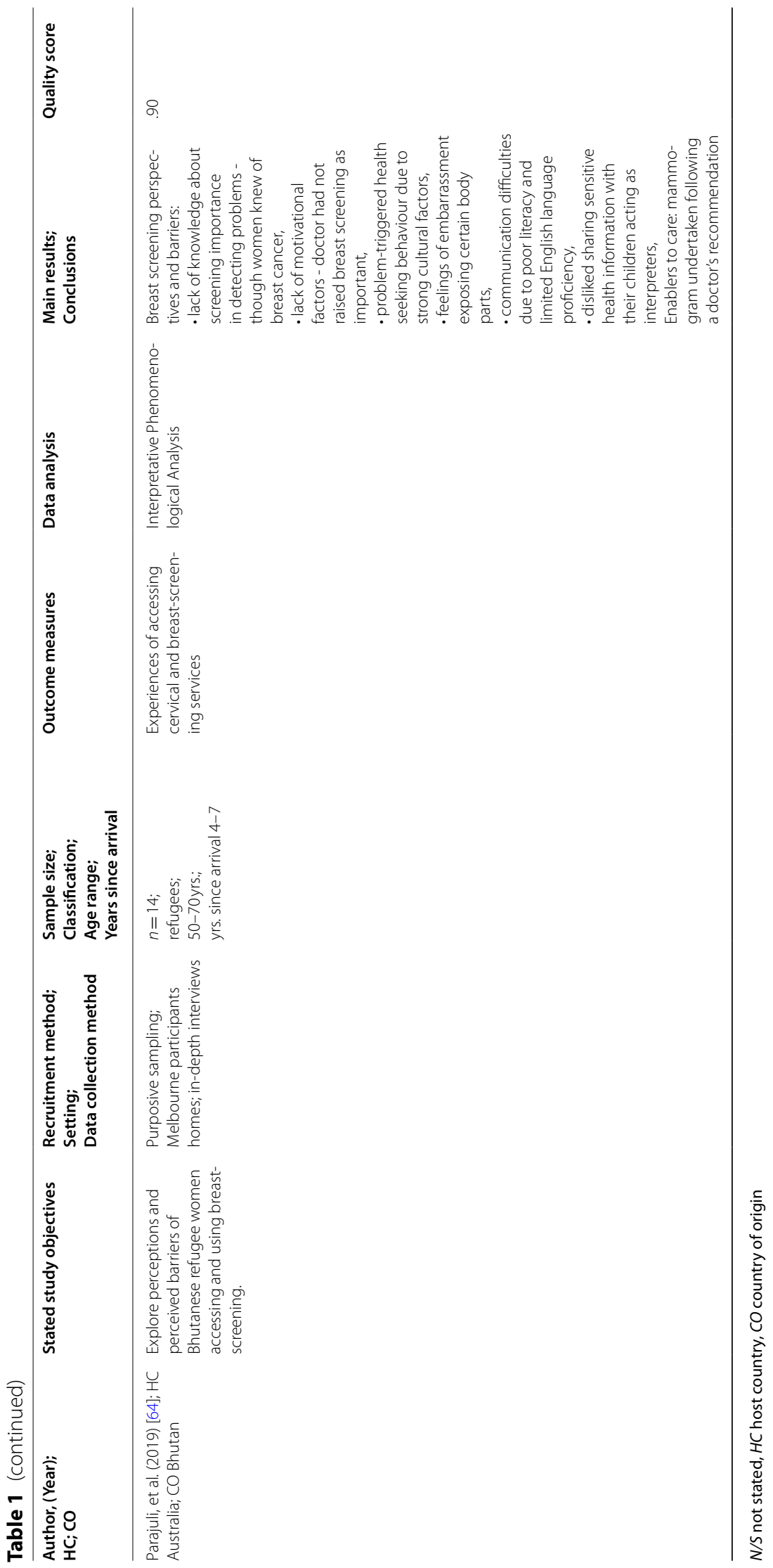




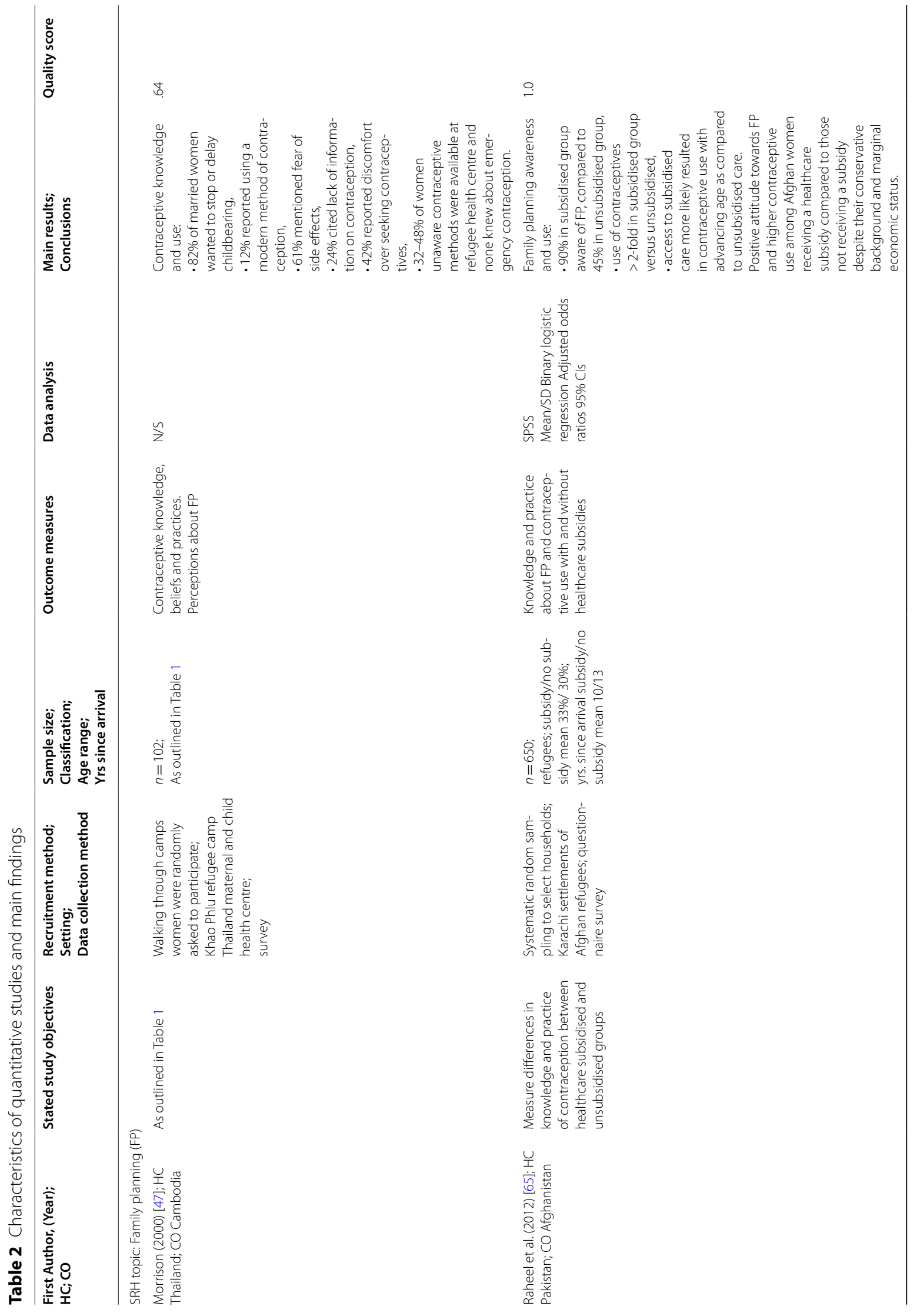




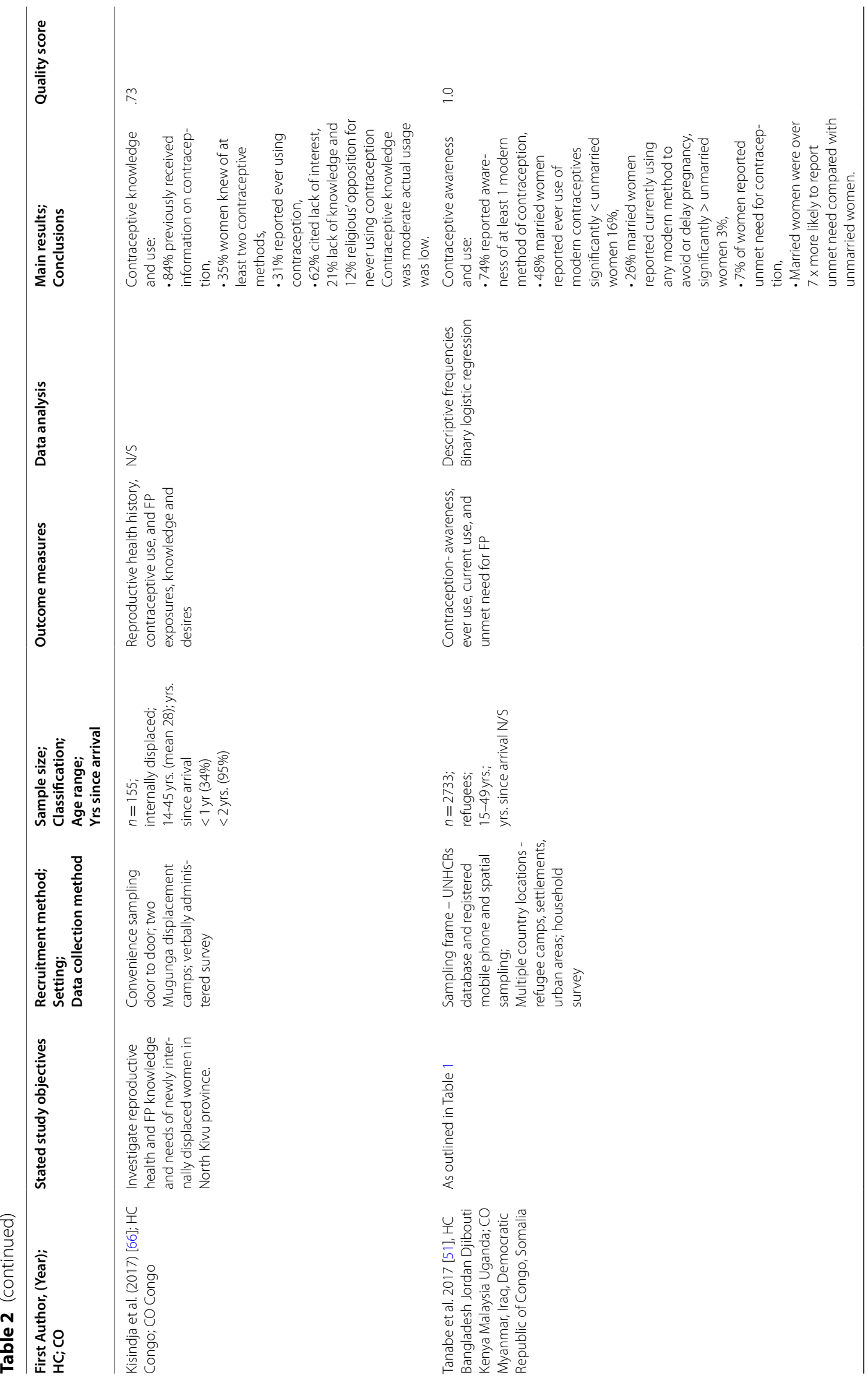




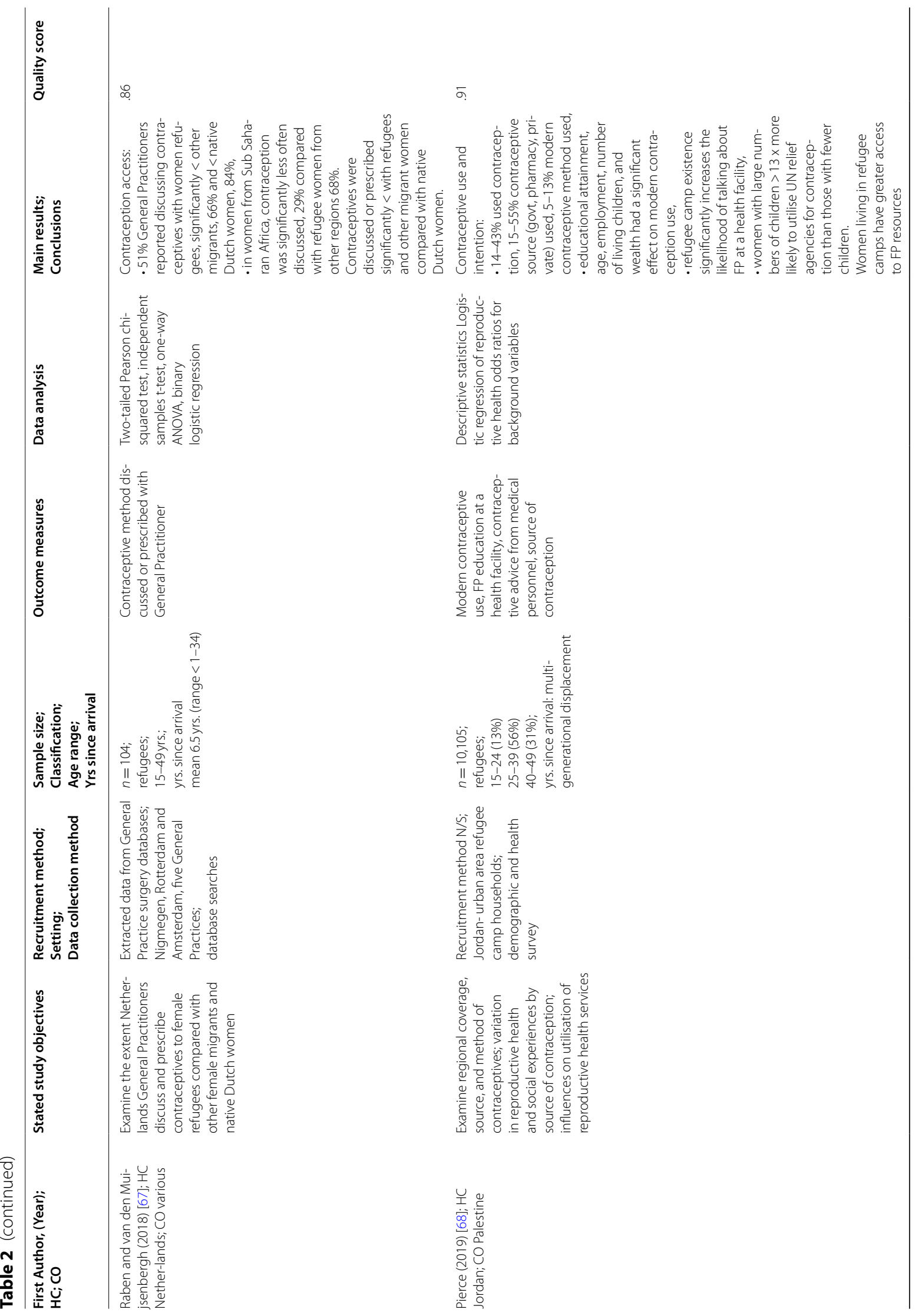




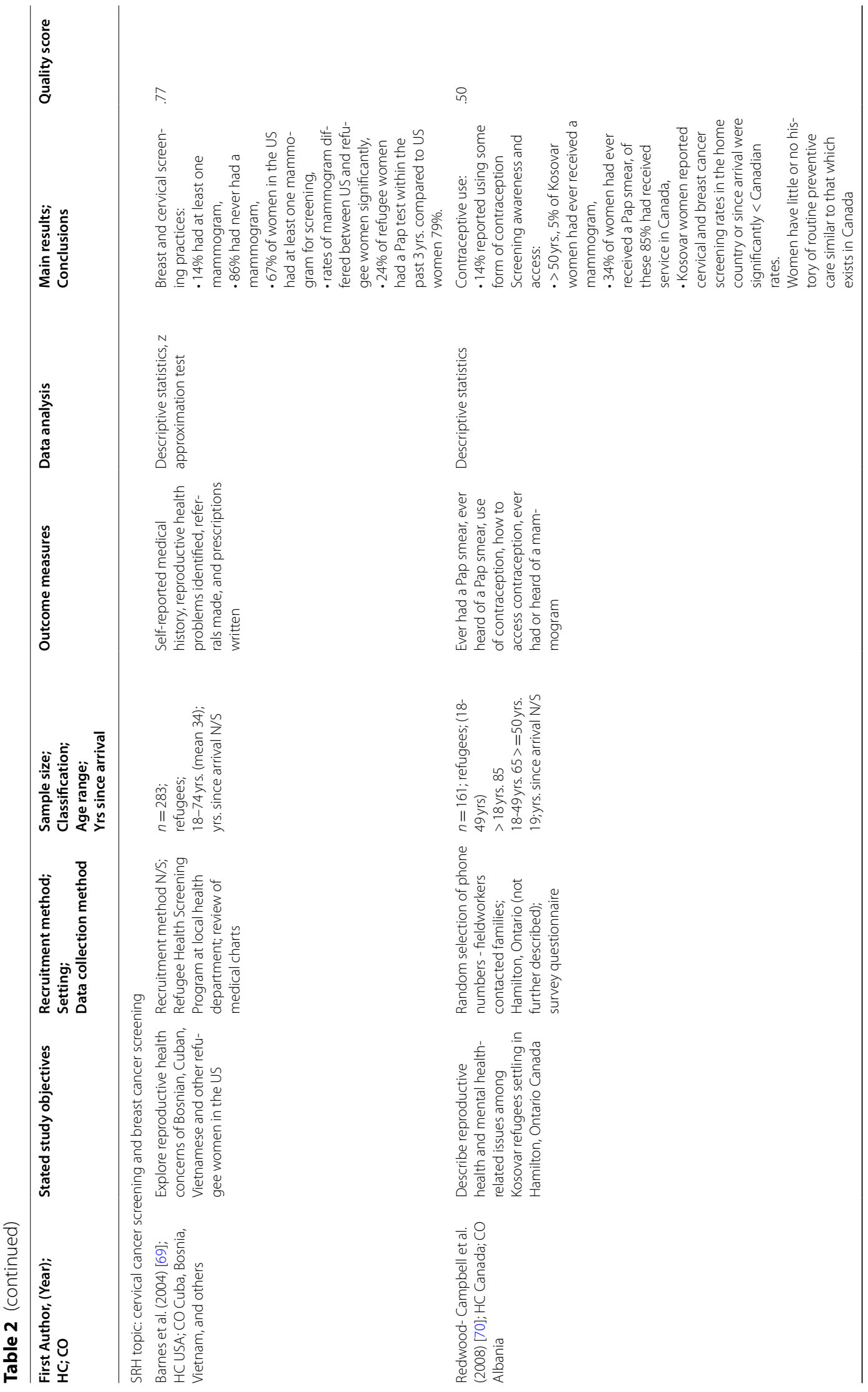




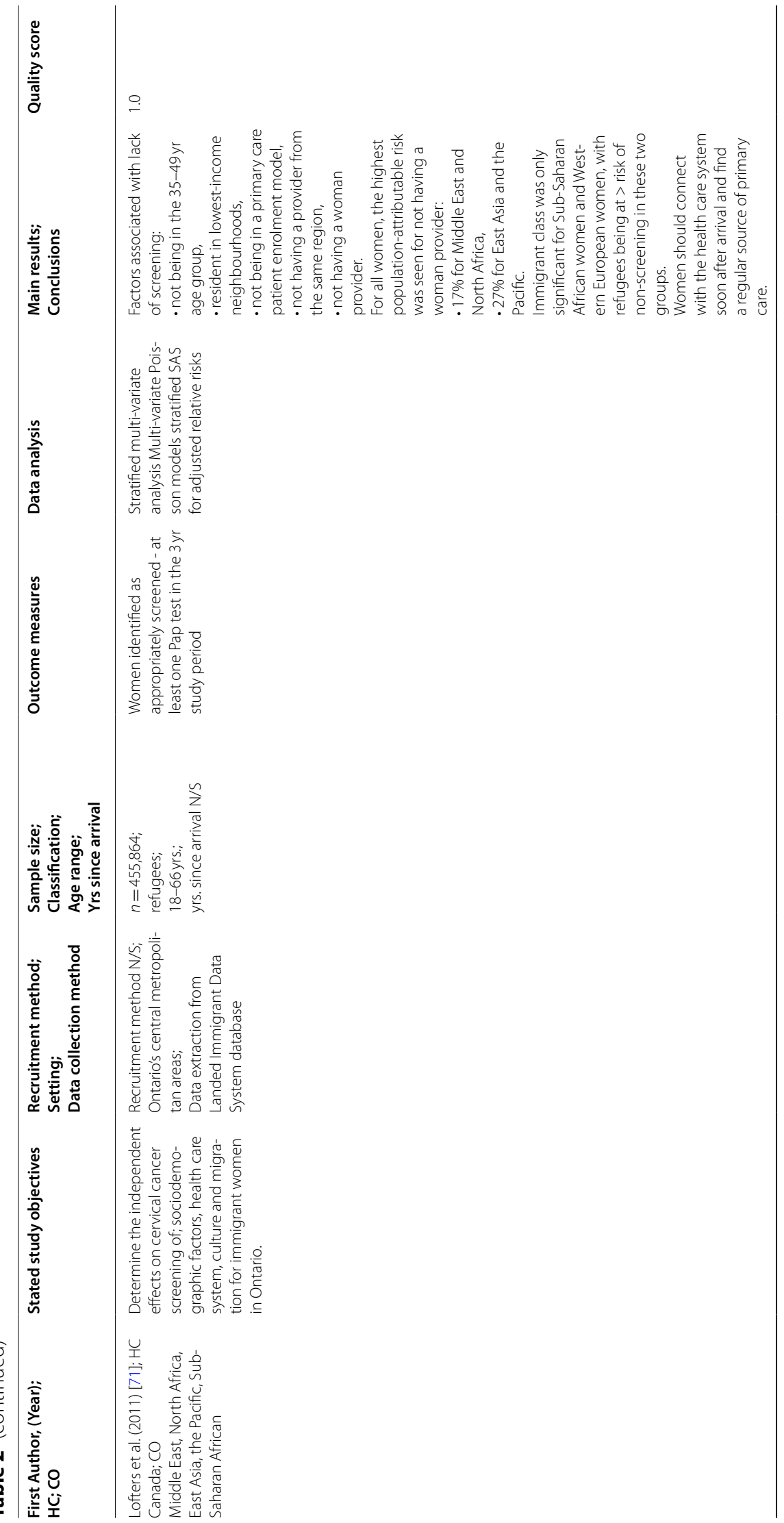




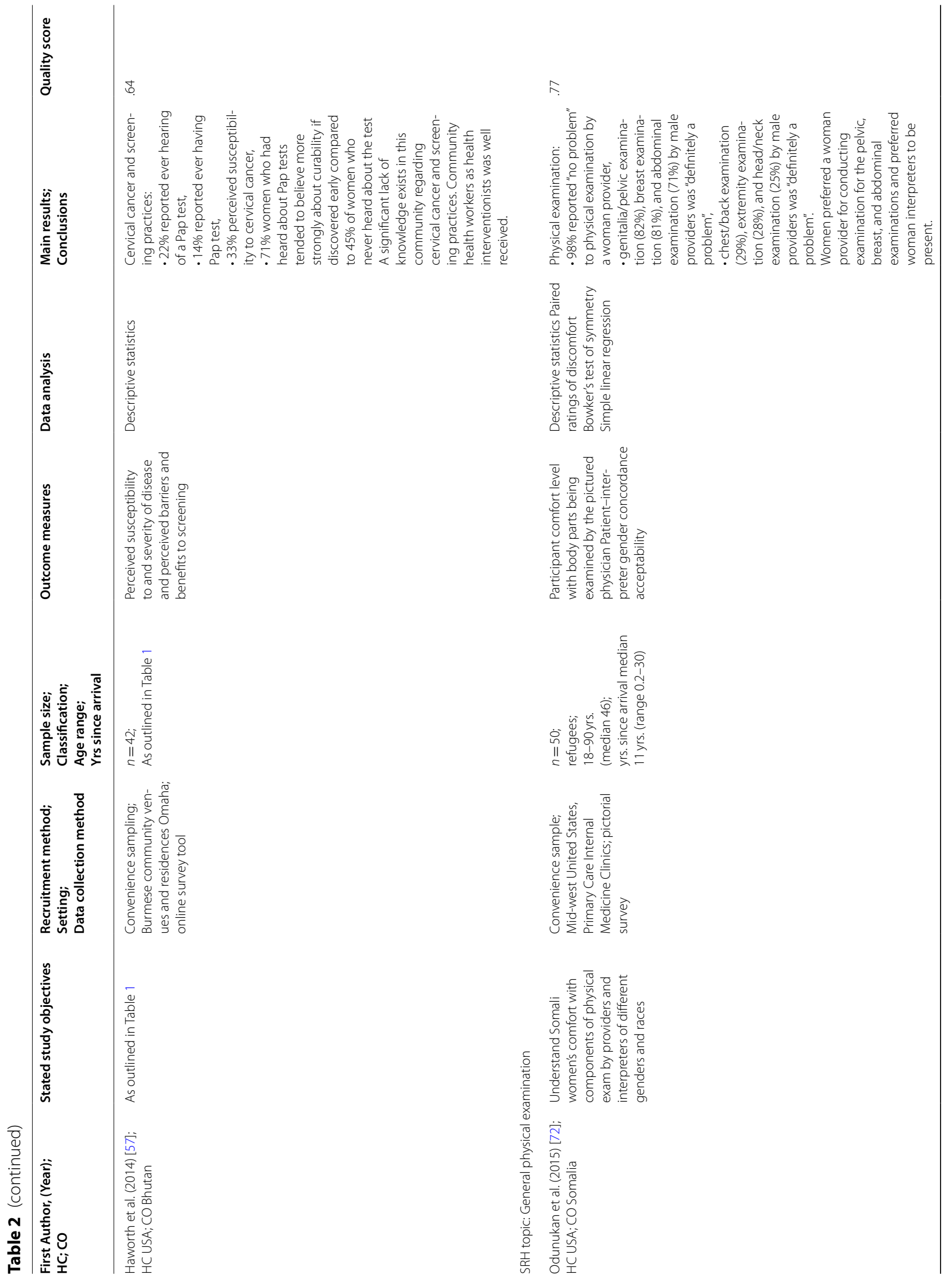




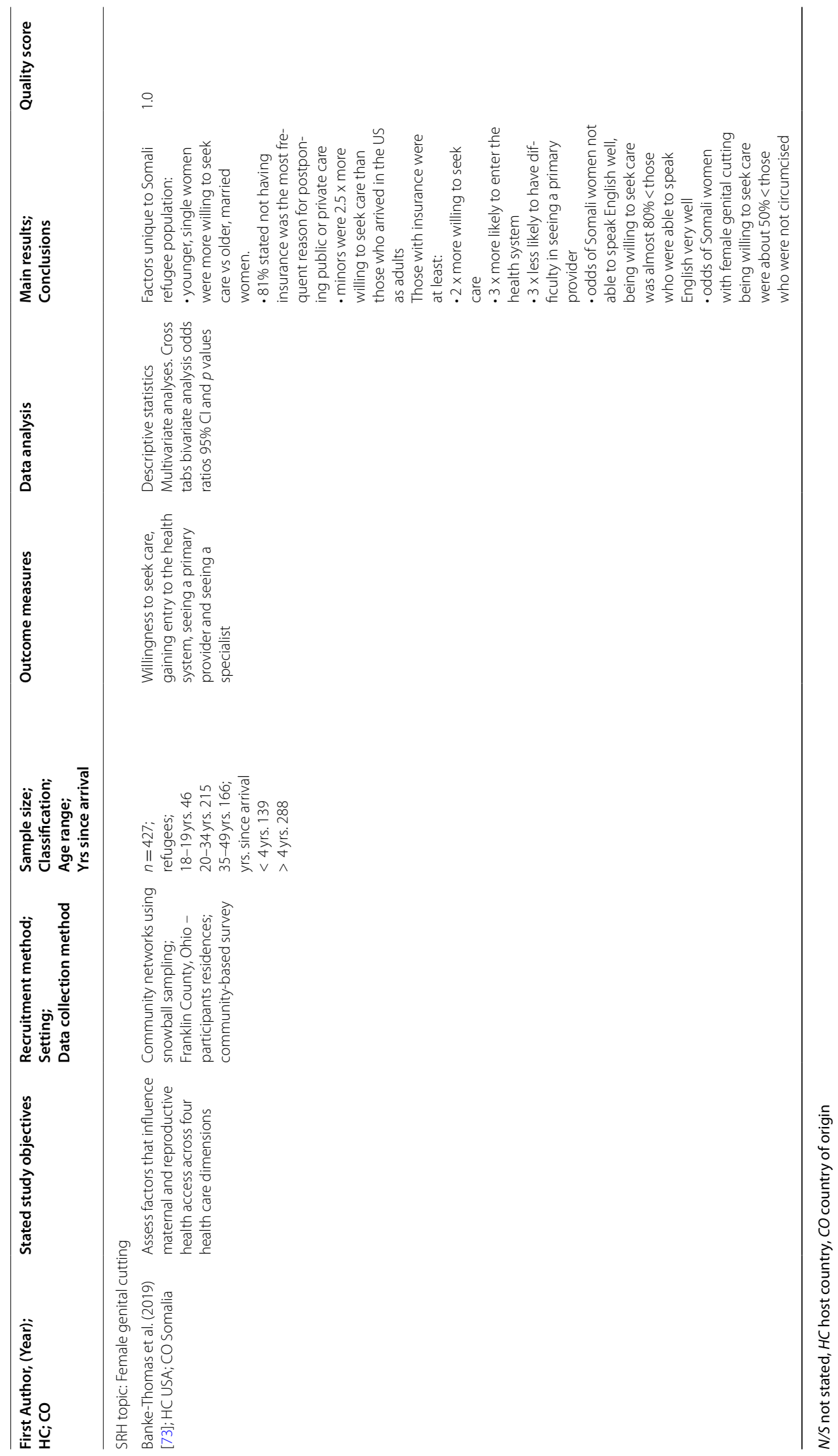


Table 3 Summary of main themes

\begin{tabular}{|c|c|}
\hline Main themes & $\begin{array}{l}\text { Sub themes (Country setting - High-income country-HIC/ Low- } \\
\text { middle-income country-LMIC) }\end{array}$ \\
\hline \multirow{3}{*}{$\begin{array}{l}\text { Interpersonal and patient encounter factors - patient interactions with health } \\
\text { care systems and HCPs }\end{array}$} & Knowledge, awareness and use of preventive SRH care (HIC and LMIC) \\
\hline & Perceived need for preventive SRH care (HIC and LMIC) \\
\hline & Language and communication (HIC and LMIC) \\
\hline \multirow[t]{4}{*}{$\begin{array}{l}\text { Health care system factors - health system factors and their impact on } \\
\text { outcomes }\end{array}$} & $\begin{array}{l}\text { Health care provider discrimination and lack of quality health resources } \\
\text { (HIC and LMIC) }\end{array}$ \\
\hline & Financial barriers and unmet need (LMIC) \\
\hline & Health care provider characteristics (HIC and LMIC) \\
\hline & Health system navigation (HIC and LMIC) \\
\hline \multirow{3}{*}{$\begin{array}{l}\text { Sociocultural factors and the refugee experience - the influence on outcomes } \\
\text { of refugee and resettlement experiences. }\end{array}$} & Family influence (HIC and LMIC) \\
\hline & Religious factors (LMIC) \\
\hline & Cultural attitudes (HIC and LMIC) \\
\hline
\end{tabular}

\section{Interpersonal and patient encounter factors - patient interactions with health care systems and HCPs}

Knowledge, awareness and use of preventive SRH care Contraception Almost all studies on contraception reported some lack of knowledge, awareness and barriers to uptake among women $[47-49,51-54,56,66$, 68]. Negative beliefs or misperceptions about side effects of contraceptive methods were evident in three high quality qualitative studies of Somali and Syrian women residing in the US and Lebanon $[49,53,56]$. Inaccurate beliefs about contraception included; consequent inability to conceive after discontinuing contraception and decreased sex drive [53], and fear that modern contraceptives cause infertility [56], menstrual irregularities and mood disorders [49]. Six studies conducted in Jordan, Democratic Republic of Congo, Thailand and other low-income countries assessed whether women had ever used contraceptives [47, 51, 66, 68], their awareness of methods of contraception [51], and information received about contraception [66]. A high quality qualitative study of Syrian women in Jordan found they had high awareness of modern contraceptive methods but limited access to contraceptive counselling and services [52]. High awareness and low use of contraception was more evident in low compared with high-income countries due mainly to overburdened health services, cultural pressures regarding fertility, poorly trained service providers, health service disrupted by conflict, distance to service delivery points, cost of transport, religious opposition, language barriers with providers, and provider biases [51, 52, 66]. In refugee camp settings contraceptive knowledge was moderate in Afghan refugee women in Pakistan, Rohingya refugee women in Bangladesh [51, 65] to high in internally displaced people in the Democratic
Republic of the Congo $[65,66]$ while actual usage was low in Cambodian refugees in the Khao Phlu Camp in Thailand [47, 66, 70]. Where the value and knowledge of contraception was moderate to high women reported approval of their friends and spouses. Women having discussions with their husbands about the number of children they should have supported contraceptive use [65]. One study reported that women themselves made the decision to use contraception [66]. Conversely, barriers for contraceptive use included the husband making decisions about the wife's access to birth control, fear of side effects, lack of information, having a current illness, expense, being too old, being unable to obtain them and husband's refusal to permit contraceptive use [47].

Cervical and breast cancer screening Knowledge, awareness and/or uptake of cancer screening was reported in nine studies conducted in high-income countries in the US [59-61, 69], Australia [62, 64], Canada [70] and South Korea [58]. Women's understanding of causes of disease and disease prevention was reported to be limited in most studies [57-62, 64, 69]. While some participants resettling in the US and Australia had heard of cervical cancer in four studies of Somali and Iraqi women [56, 60-62], studies of other ethnic groups had variable and at times inaccurate knowledge of cancer aetiology [59$62]$, cancer prevention $[57,58,61,62]$ and the purpose of screening $[64,69]$. One study in the US reported Iraqi women would undergo screening only if provided with explanations of the exam and its necessity [61] which corroborates the importance women placed on doctors' screening recommendations [49, 64]. A study of HCPs' views in the US reported that women from various ethnicities were unfamiliar with tests to identify disease at its early stages [74]. 
Less knowledge and awareness of HPV and HPV vaccination compared with cervical screening was evident in two US studies of Somali and Bhutanese women [57, 60] with varying understanding of whether the virus causes cancer [60] (HPV vaccination has been offered in the US since 2006). Cross sectional surveys measuring rates of breast and cervical screening among refugee and displaced women found lower screening rates when compared with the host country populations of the US and Canada [57, 69, 70]. Barriers to screening identified in Somali and Bhutanese refugee women and refugee women from other ethnic groups were limited or no knowledge regarding cervical cancer and its prevention $[57,60]$.

Perceived need for preventive SRH care Unfamiliarity with preventive care and low perceived need for it was apparent in seven studies of Somali, Iraqi, Bhutanese and North Korean women conducted in the US [56, 57, 59, 61], Australia [62], Canada [70] and South Korea [58]. The belief that only symptomatic women need to undergo screening was common in eight studies [5659, 62-64, 69], with absence of symptoms being one reason for not having cervical [58] or breast screening [64]. This resulted in women not seeking preventive care $[62,64]$ or delaying seeking care until a problem became unbearable [61]. One high quality study of Bosnian, Iraqi and Somali women found doctors in some countries of origin focused only on acute, not preventive care [63]. A study of US HCPs' views found that refugee women often sought care only when symptomatic [74].

Language and communication Access to care related to communication was reported in four studies on contraception $[48,51,54,56]$, three on cervical and breast cancer screening $[57,59,64]$ and one on female genital cutting [73]. Limited English language proficiency [57, $59,64,73]$ and poor literacy impacted on access to care $[64,73]$ and were challenging for HCPs and Somali and Eritrean women alike $[48,54,74]$. In two studies the real communication barrier was reported to be that telephone or in person interpreters did not understand the concepts being discussed $[48,59]$. Other studies reported few, if any, translation services available in any healthcare facilities [54, 59], HCPs being unaware of language requirements [48] and women feeling rushed and unable to see or hear telephone interpreters [59]. Communicating with interpreters and providers during reproductive health consultations was reported to lead to embarrassment, shyness or stigma for some women $[47,48,59,61$, $63,64]$.

\section{Health care system factors - health system factors and their impact on outcomes}

Health care provider discrimination and lack of quality health resources HCP discrimination described as poor communication and perceived lack of care [54], judgemental approaches and disrespectful behaviour in the provision of contraception impacted on refugee women in low income country settings in access to care [50]. A lack of affordable and acceptable methods of contraception offered to women in Jordan and other refugee camp settings, [51,52] was also identified as a barrier to contraceptive use in studies of Syrian and Eritrean women in lowincome country settings [50-52, 54]. HCPs in Lebanon reported their own discrimination in the form of negative attitudes towards Syrian women; one study suggesting women were irresponsible, unreliable and ignorant when seeking care [50]. Other studies in low-income countries indicated poor or second-class treatment occurred due to poor communication, inadequate length of time required address women's needs, providers own attitudes and fears towards asylum seekers in Israel [54] and gaps in their own skills and knowledge in providing care [51].

Studies of HCPs' views conducted in low-income countries of Lebanon, Israel and others found limited acceptable contraceptive methods impacted on accessing care $[50,51,54]$. An associated lack of quality resources and perceptions of low-quality care such as provision of incorrect information, incorrect prescriptions, poor hygiene in SRH care were cited in high- and low-income settings $[51,54,55]$. Women's negative clinical encounters with HCPs in low-income country settings coupled with fear of maltreatment when seeking contraception, unwillingness to have contraception prescribed and time constraints were reported experiences of discrimination $[47,50,54]$. Discrimination appears to have continued following resettlement. One Dutch study reported fewer discussions about contraception between General Practitioners and refugee and displaced women compared with other migrants or host country populations [67]. Another US study reported poor recognition of women's experience of physical pain by their HCP [61]. Fear and mistrust in seeking care as a result of trauma, sexual violence and bad experiences of screening and diagnosis were also evident among refugee women of various ethnicities in studies conducted in the US and Australia [59, 62, 63].

Financial barriers and unmet need Cost was cited as the main barrier to preventive care by many women [49, 50, 54, 59] and HCPs [54] particularly in low-income settings where access to free healthcare was not universal. 
Low awareness of the availability of free contraceptive services was cited in two studies in Lebanon and Cambodia [47, 49]. Afghani and Palestinian refugee women in informal settlements and refugee camps in neighbouring countries were between two and 13 times more likely to use contraceptives if costs were subsidised [65, 68]. A South Korean study of women refugees from North Korea found cost deterred women from cervical screening [58]. In one high quality study, lack of health insurance had a strong association with women's access to maternal and reproductive health care across the continuum of primary care services including family planning and was the most common reason for postponing a visit to primary care [73].

Health care provider characteristics In several studies women from different ethnic groups expressed concern about receiving care from male HCPs $[58,59,62,72]$ with some choosing to forgo care rather than discuss reproductive health topics or undertake cervical screening [48, 71]. Odunukan and others found Somali women preferred a woman provider for physical examinations [72]. HCPs showed insight into their own limitations with regard to caring for refugee and displaced women. Despite women being receptive to screening information in early resettlement, HCPs reported that lack of knowledge, concerns about the timing of information delivery and their own discomfort were barriers to discussing screening [74].

Health system navigation The complexity of healthcare systems impacted on access in seven studies, though the nature of the difficulties varied according to low- or highincome country setting $[47,51,54,57,59,63,69]$. In lowincome settings distance to service point, lack of transport and the fragmented nature of service provision [51, 54] were identified as barriers to contraceptive care even when clinic opening times/ locations and contraceptives were available [54]. Navigating and understanding the health system and making appointments were barriers reported in high-income host countries [59, 63, 69].

\section{Sociocultural factors and the refugee experience - the influence on outcomes of refugee and resettlement experiences}

Family influence Ten studies in both high- and lowincome country settings suggested family influence affected women's utilisation of contraception, breast and cervical screening $[47-53,55,58,60]$. Husband's resistance to birth control and having the final decision about contraceptive use $[49,51,53]$ impacted on access. Acceptance by women about the dominant role of the male partner in the decision-making [50, 52], family's interference [49] as well as deferral to HCPs decision making [48] also impacted on contraceptive use across high and low-income countries. HCPs in Thailand reported that Cambodian women were considered candidates for contraception only after approval from their husbands [47] despite women wanting to stop or delay childbearing [47]. Conversely, a Jordanian study of displaced Palestinian women serviced by the United Nations Relief and Works Agency found they had greater access to health-related resources such as contraception than the host population [68].

Religious factors Religious opposition to contraception was apparent in high and low-middle income country settings $[48,51,53,56,66]$. It was taboo for a woman to state she did not want more children [53], nor to use modern birth control as it was forbidden by religion [48]. Religious teachings actively discouraged modern contraceptive use in five of the six population groups included in one multi-country study [51]. The importance of marriage and fidelity for Cambodian women in Thailand created a barrier to using contraception [47]. However, in other ethnic groups such as internally displaced Congolese women, religious opposition to contraception was low [66]. Amongst Somali women resettling in the US, contraception was more acceptable when framed as temporary assistance for birth spacing as this agreed with the tenets their religion [55]. SRH services differ in each resettlement country. This may provide insight on why the barriers to contraception varied across ethnicity and host country. HCPs in the US reported that despite there being strong opposition to contraception in Somali culture and religion, they asked for and used contraception upon resettlement [48].

Cultural attitudes Traditional cultural attitudes towards fertility influenced modern contraceptive use following displacement [51, 52, 56, 73]. In one qualitative study of Syrian women in Jordan, pressure to marry and begin childbearing early was the main barrier for some (young and unmarried) women but not others [52]. In Somali culture, one US study reported that contraception is not discussed with young unmarried women and girls as pre-marital sex is stigmatized and disapproved of [56]; a finding supported by another study among unmarried Iraqi, Burmese, Rohingya, and Somali women in refugee resettlement camps in several low-income countries [51].

Engagement with HCPs was also reported to influence access to contraception. In a group of Somali bantu women in the US considerable cultural deference given to authority figures and an accompanying lack 
of self-advocacy in interactions with HCPs influenced access [48]. Tanabe and colleagues [51] reported that emergency contraception was offered to survivors of sexual assault by HCPs working in a gender-based violence program in refugee resettlement camps in low-income countries. However, they reportedly disapproved of making emergency contraception available for non-sexual assault cases, citing it could promote promiscuity [51]. For Somali women resettled in the US, being circumcised was found to impede entry into the health system and access to primary HCPs [73].

Positive relationships with and positive attitudes towards doctors and other HCPs were reported to improve access to care by Burmese and Bhutanese arrivals in the US [59, 63]. A key theme for women from these ethnic groups was the preference for women providers due to the cultural considerations of modesty and privacy and the association with honour and virtue. Other studies in the US and Jordan found the presence of trusted woman providers and interpreters improved the cultural acceptability of services and increased uptake of contraception and cervical screening $[52,59,71,74]$. Intervention strategies to promote cervical screening and HPV vaccination were identified in three studies. They were language and culture specific web, telephone and community-based programs [60], free biennial screenings [58] and screening self-collection which is a particularly effective intervention for refugee and displaced women for reasons outlined above [62]. Congolese women resettled in the US and Syrian women resettled in Lebanon reported more equal relationships and increased empowerment regarding women's changing roles in decision making about contraceptive use following resettlement $[50,55]$. Desire for educational achievement and the absence of extended family were identified as factors facilitating contraceptive use in one US study of Somali women [56]. Support from husbands in health decisions, encouragement from partners and other family members were reported to impact positively on women's decision to have cervical screening in the US and Canada [58, 60]. Interpreters conveying educational messages about cervical screening and HPV vaccination were reported to increase take-up of screening $[57,60]$. Furthermore, interpreters in the US with some medical knowledge who were members of the Somali refugee community and acted as 'refugee mentors' improved access to care [73].

\section{Discussion}

To our knowledge this is the first systematic review of the evidence that explicitly addresses access to preventive SRH care for refugee, asylum seeker and internally displaced women. Most research has focused on identifying barriers, much less on enablers of access to care. There was consistent evidence about three factors impacting on access: patient experiences of clinical encounters, the host countries' healthcare systems and the sociocultural context of a refugees' journey.

There are few investigations of HCPs' perspectives and their experiences of providing SRH care for refugee and displaced women. This limits the opportunity to ascertain consistencies and inconsistencies between refugee and displaced women and HCPs' views. Most investigations were of refugees with only one each of internally displaced people and asylum seekers limiting the opportunity to compare the differences between these groups.

\section{Strengths and limitations of the systematic review}

A comprehensive search of five databases was conducted using a published protocol. It was supplemented by citation searches, so all relevant studies were likely to have been identified. Study selection bias was minimised by having pre-set inclusion criteria and having three authors undertake full text screening independently, with differences in opinion resolved in discussions among all authors. Two authors independently assessed the quality of the included studies using a well-established quality assessment tool [45].

The varied study designs, and their use of qualitative, quantitative and mixed methods precluded meta-analysis of findings. However, the inclusion of methodologically diverse studies and the narrative synthesis enabled a comprehensive understanding of SRH care access for refugee and displaced women. The foundation of the qualitative evidence was complementary to quantitative results, presenting a complete picture of women's experiences. For instance, quantitative studies estimated prevalence of contraceptive knowledge, contraceptive information provision, and prevalence of use of contraception amongst refugee and displaced women. Whereas, qualitative studies elucidated the reasons why women's uptake of contraception was low in some settings. Qualitative studies also described women's views on their decision to use contraception and perceptions of service availability, accessibility, and quality.

Similarly, quantitative studies established rates of breast and cervical screening as well as cancer knowledge and awareness among refugee and displaced women. Whereas qualitative studies provided details on the overlapping complexities and context of why women were aware of breast and cervical screening but had not accessed the services, despite its availability in high income countries.

A strength of the narrative synthesis is that it enabled overlaying of themes across studies. It also allowed the comparison of findings and relationships between 
studies. When interconnected points of similarity are identified and shaped in a narrative synthesis, findings are likely generalisable and can be used to inform policy and practice [75].

The exclusion of non-English language articles may have meant that relevant publications in other languages were not included. We therefore acknowledge that the included articles may not reflect all cultural perspectives. Furthermore, it is possible that the searches did not identify studies where refugees, asylum seekers or internally displaced people were referred to as 'migrants' or 'immigrants'. The selected studies focused mainly on women with refugee status already determined in the destination country. There may be additional barriers for internally displaced people and asylum seekers that are not described fully in this review due to the limited number of studies of women in these groups. The limited number of internally displaced people and asylum seeker studies also makes it difficult to draw subgroup comparisons.

\section{Strengths and limitations of the included studies}

Overall, the quality of the studies was high with none judged as poor quality. Study designs and methodologies were appropriate for the studies' aims and closely aligned with their outcome measures. A strength of both qualitative and quantitative studies was that most data came from primary sources - the women themselves, through a variety of methods. The definition of 'refugee' was consistent across studies which suggests the results reflect the experiences of refugee and displaced women.

Of the qualitative studies, few reported on the quality assessment criteria of "reflexivity". Reflexivity is the acknowledgement of cultural differences and asymmetry in the researcher - participant relationship and how these may affect the study method used, participant recruitment, and study findings and conclusions [76].

\section{Methodological quality}

Many studies used convenience sampling strategies. This may have resulted in an overrepresentation of women already seeking care, or a bias toward those with greater ability to navigate the health system. The studies would more accurately represent the factors impacting on access to care had recruitment gone beyond and included community members yet to engage with health and community services. Qualitative studies used either focus groups or interviews; methods considered the most appropriate for eliciting views on sensitive topics in vulnerable populations [77, 78]. Studies used face to face bilingual researchers or interpreters, a recognised method for overcoming challenges of participants low literacy and/or low health literacy [79].
Quantitative studies were strengthened by using validated survey instruments translated into participants' language. However, some instruments had not been cross-culturally validated and back translated. Most surveys were administered individually and verbally, modes of delivery considered the least burdensome for those with low literacy [80].

\section{Overview of findings}

There are many barriers to SRH care in both high and low- and middle-income country settings, including women's low perceived need for preventive care, cultural attitudes and beliefs about family planning, cervical and breast cancer screening and HPV vaccination, stigma and shame surrounding women's access to and use of SRH care services, discriminatory practices, lack of women HCPs, culturally competent care, and language barriers. However, our review indicates that many barriers are exacerbated by the refugee context and that additional barriers to SRH exist in LMIC settings. Deficiencies in infrastructure and transport, costs of transport to access services, and fragmentation of the health care system, especially in refugee camp settings and in poorly resourced resettlement countries, limit women's access to SRH care and support. Male partners' influences in decision-making about women's SRH can limit access to contraceptive counselling and services. Health provider biases in providing contraception, poor awareness of SRH services, a lack of privacy and confidentiality, and respectful and woman-friendly SRH services were other barriers in many low- and middle-income resettlement settings.

Conversely, enablers to SRH care were mainly reported in high income countries. Resettlement in high income settings found women's agency and self-determination are highly valued and are reflected in principles of service provision including for women who are refugees when accessing SRH. This was probably reflected in women reporting greater ownership of their SRH care, [48], increased equality in their personal relationships, [55] and more positive relationships with their HCPs $[59,63]$.

\section{Patient experiences of clinical encounters}

The breadth of the studies reviewed was reflected in the seventeen different cultural and ethnic backgrounds identified conducted across sixteen high- and lowincome countries. Despite this diversity, similar patterns of access to SRH care were reported. One consistent finding was that unfamiliarity with preventive SRH care and low health literacy impacted on accessing care. Key components of health literacy were identified throughout the review; difficulties navigating the health system, lack of knowledge of disease aetiology, poor health care 
practices, limited sense of self-advocacy and the challenges of taking ownership of one's health. These factors were exacerbated by women's lack of autonomy and this quantitative study found both physical and emotional domestic violence had a significant impact on refugee women receiving contraception [68].

Communication barriers were consistently highlighted. Irrespective of women's ethnic background or host country language barriers coupled with poor cultural competence in service provision impacted on access. Communication barriers are known to create difficulties negotiating health systems [81] and decrease the quality of healthcare once refugee and displaced women are engaged in the system $[82,83]$. The lack of and poor quality of interpreters as well as interpreters' lack of health/ SRH knowledge were also highlighted [48]. When discussing $\mathrm{SRH}$, engaging qualified medical interpreters is preferred by refugee and displaced women [84] and has been shown to enhance the delivery of SRH care to women with limited English proficiency [85].

\section{Host countries' health care system}

Women consistently reported experiencing discrimination and disrespectful care though this was more evident in low-income countries informal resettlements arrangements $[50,51,54,61]$. Cultural competence is the ability to participate ethically and effectively in personal and professional intercultural settings. It requires being aware of one's own cultural values and respectful of others values, beliefs, traditions and customs [86]. Culturally competent practice impacts on health care experiences but is challenging for many HCPs [7, 87]. Poor cultural awareness results in incorrect assumptions about refugee health needs which in turn results in decreased quality of health care and low health service utilisation [88], which was highlighted in both high- and low-income countries in this review.

Gender discordance is the discrepancy between the gender of the patient and the HCP [89]. Patient - provider gender discordance was a consistent barrier across SRH topics, ethnic groups and host country settings. Being seen by a woman provider was a key influencing factor in accessing SRH care $[50,58,64]$. The review highlighted that women were more likely to seek SRH care and be more comfortable expressing their needs with women HCPs and interpreters.

\section{Sociocultural context of a refugees' journey}

Many sociocultural barriers also exist for women from migrant backgrounds who are not refugees [90]. However, refugee and displaced women may experience violence, trauma in their countries of origin and prolonged and dangerous in transit journeys prior to arrival in a resettlement country. Consequently, there are additional and more acute sociocultural barriers to accessing SRH for this group upon arrival. These barriers include family, cultural and religious influences as well as knowledge, awareness and use of SRH care $[9,90]$.

Specific barriers to care for vulnerable subgroups of refugee and displaced women were identified. Younger unmarried women [50] and women who had experienced female genital cutting [73] faced additional layers of disadvantage in accessing SRH care. In this review the patterns of access of those sub-groups were difficult to establish given the limited number of related studies.

There was uniformity of findings relating to positive influences on access to SRH care across ethnic groups and healthcare contexts. Interpersonal factors included establishing trust, confidence and communication between refugee and displaced women and HCPs, HCPs training in cultural competency, provision of quality medical interpreters and patient-provider gender concordance. This suggests building meaningful relational connections, acknowledging refugees' journey, establishing rapport, taking the time needed to communicate and access to women providers are important in the provision of care to refugee and displaced women.

\section{Implications for clinical practice and future research Clinical practice}

Key solutions to addressing access to care lie in strengthening SRH education for refugee and displaced women, including offering culturally sensitive information about the importance of preventive SRH care and how the health system functions in the host country. Such initiatives are known to lead to increased utilisation of services [91] and better SRH outcomes [74, 92].

Interventions to improve health literacy might include offering preventive SRH education in appropriate languages, targeting reading levels and design of printed material and using the Teach-Back method in face to face education [93], supporting health system navigation, and promoting self-efficacy and self-advocacy skills.

\section{Policy}

Ongoing HCPs professional development and education encompassing culturally competency and awareness of SRH needs leads to better health care provision of ethnically diverse groups [94]. Cultural competence training has been developed to improve access to care [95], and has resulted in better quality care $[96,97]$ and reduced discrimination in settings with diverse ethnic groups [98]. Ensuring adequate refugee-specific health services and well-trained culturally sensitive HCPs, such as specialist General Practitioners, refugee health nurses, and bicultural healthcare workers may improve SRH care for refugee and displaced women. Health policy aimed 
at providing bilingual community support workers and medical interpreters as advocates with knowledge and sensitivity to address SRH topics would benefit women during resettlement. Providing an understanding of the complex SRH care needs of refugee and displaced women in undergraduate and professional development programs would further facilitate access. Ensuring specific health literacy education modules for primary HCPs as a component of their continuing professional development should be a priority. Such initiatives should be a priority in high-income resettlement countries where standards and guidelines can be set and adapted appropriately to low-income country settings with less resources.

Addressing gender discordance by employing more women General Practitioners, increasing the scope of practice for refugee health nurses, and giving women the option of choosing the gender of practitioners may facilitate care. This, together with providing adequate human resourcing allowing longer consultation times to accommodate cultural needs, to listen and develop women's trust and confidence and confirm screening and contraception information is understood could enhance access to care.

\section{Future research}

HCPs knowledge and behaviour toward refugee and displaced women significantly impact women's access to SRH. More research is needed to understand HCPs educational and cultural competency needs. Furthermore, identifying HCPs understanding of health literacy principles to support them in developing strategies towards facilitating women's health literacy is needed. Identifying additional positive influences on access to care for refugee and displaced women, particularly in the early resettlement period when women feel more empowered to make their own decisions regarding SRH care, should be a priority. Further research in the area of access to preventive SRH care for women who have experienced female genital cutting is also warranted.

\section{Conclusion}

The findings of this review show that to improve access to culturally sensitive and patient-centred care SRH care in primary healthcare settings, interpersonal factors including knowledge, awareness perceived need for and use of preventive SRH care; language and communication barriers, health system factors including HCP discrimination, lack of quality health resources; financial barriers and unmet need; HCP characteristics; health system navigation and sociocultural factors including family influence; religious and cultural factors need to be addressed. The findings can inform practice, public health policy, and health professional education to ensure refugee and displaced women have access to quality preventive SRH care in primary care settings, particularly in low-incomes countries where most refugees seek resettlement.

\section{Abbreviations \\ CO: Country of origin; FP: Family Planning; FGD: Focus Group Discussion; HC: Host country; HCP: Health Care Provider; HPV: Human Papilloma Virus; OCP: \\ Oral contraceptive pill; SRH: Sexual and Reproductive Health; US: United States of America.}

\section{Supplementary Information}

The online version contains supplementary material available at https://doi. org/10.1186/s12889-022-12576-4.

Additional file 1. Selection criteria.

Additional file 2. Database search strategy.

Additional file 3. Quality assessment of quantitative studies and quantitative component of mixed methods.

Additional file 4. Quality assessment of qualitative studies and quality component of mixed methods.

\section{Acknowledgements}

JF is supported by the Finkel Professorial Fellowship which receives funding from the Finkel Family Foundation. ND holds an Australian Government Research Training Scholarship.

\section{Authors' contributions}

The search strategy was devised by ND with the assistance of LR. ND contributed to the PROSPERO submission. Titles and abstracts were searched by ND. Screening of full text articles was undertaken by ND, JF and $\mathrm{KH}$ independently. Quality assessment was conducted by ND, JF and KH. The data extraction, analysis and narrative synthesis involved ND, with JF and $\mathrm{KH}$ bringing a wider perspective to the analysis. All authors contributed to the development of the manuscript and approved the final version.

\section{Authors' information}

All listed authors have approved the manuscript before submission, including the names and order of authors.

Funding

There was no funding source for this particular study.

\section{Availability of data and materials}

The datasets used and/or analysed during the current study are available from the corresponding author on reasonable request.

\section{Declarations}

Ethics approval and consent to participate

Not applicable.

\section{Consent for publication}

Not applicable.

\section{Competing interests}

We declare no competing interests.

\section{Author details}

${ }^{1}$ Global and Women's Health, School of Public Health and Preventive Medicine, Monash University Faculty of Medicine Nursing and Health Sciences, Melbourne, VIC, Australia. ${ }^{2}$ The lan Potter Library, The Alfred Hospital, Melbourne, Victoria, Australia. 
Received: 7 April 2021 Accepted: 6 January 2022

Published online: 27 February 2022

\section{References}

1. United Nations High Commissioner for Refugees. Figures at a Glance, Geneva. 2020 https://www.unhcr.org/en-au/figures-at-a-glance.html. Accessed 20 Oct 2020.

2. United Nations High Commissioner for Refugees. What is a refugee? Geneva. 2020 https://www.unhcr.org/en-au/what-is-a-refugee.html. Accessed 11 Nov 2021.

3. United Nations High Commissioner for Refugees. Global trends forced displacement. Geneva: UNHCR; 2019. https://www.unhcr.org/60b63 8e37/unhcr-global-trends-2020.html Accessed 11 Nov 2021.

4. United Nations High Commissioner for Refugees. Protracted Refugee situations: the search for practical solutions. Geneva: UNHCR; 2006 https://www.unhcr.org/4444afcb0.pdf Accessed 1 June 2020

5. Crosby SS. Primary care management of non-English-speaking refugees who have experienced trauma: a clinical review. JAMA. 2013;310(5):519-28.

6. Dowling A, Enticott J, Kunin M, Russell G. The association of migration experiences on the self-rated health status among adult humanitarian refugees to Australia: an analysis of a longitudinal cohort study. Int J Equity Health. 2019;18(1):130.

7. McKeary M, Newbold B. Barriers to care: the challenges for Canadian refugees and their health care providers. J Refug Stud. 2010;23(4):523-45.

8. Chiarenza A, Dauvrin M, Chiesa V, Baatout S, Verrept $H$. Supporting access to healthcare for refugees and migrants in European countries under particular migratory pressure. BMC Health Serv Res. 2019;19(1):513.

9. Ivanova O, Rai M, Kemigisha E. A systematic review of sexual and reproductive health knowledge, experiences and access to services among refugee, migrant and displaced girls and young women in Africa. Int J Environ Res Public Health. 2018;15(8):1-12.

10. Seyife A, Fisseha G, Yebyo H, Gidey G, Gerensea H. Utilization of modern contraceptives and predictors among women in Shimelba refugee camp, northern Ethiopia. PLoS One. 2019;14(3):e0212262.

11. Bakesiima R, Cleeve A, Larsson E, Tumwine JK, Ndeezi G, Danielsson KG, et al. Modern contraceptive use among female refugee adolescents in northern Uganda: prevalence and associated factors. Reprod Health. 2020;17(1):67.

12. Jennings L, George AS, Jacobs T, Blanchet $K$, Singh NS. A forgotten group during humanitarian crises: a systematic review of sexual and reproductive health interventions for young people including adolescents in humanitarian settings. Confl Heal. 2019:13:57.

13. Spiegel PB, Bennedsen AR, Claass J, Bruns L, Patterson N, Yiweza D, et al. Prevalence of HIV infection in conflict-affected and displaced people in seven sub-Saharan African countries: a systematic review. Lancet. 2007;369(9580):2187-95.

14. Parish A. Gender-Based Violence against Women: Both Cause for Migration and Risk along the Journey: Migration Policy Institute; 2017 https://www.migrationpolicy.org/article/gender-based-violence-again st-women-both-cause-migration-and-risk-along-journey. Accessed 2 Oct 2020

15. World Health Organisation. Universal health coverage for sexual and reproductive health. Geneva. 2020 https://www.who.int/reproductivehea Ith/publications/financing-uhc-for-sexual-reproductive-health-evidencebrief/en/. Accessed 5 Nov 2020.

16. United Nations. Transforming our World: The 2030 Agenda for Sustainable Development. 2015. https://sustainabledevelopment.un.org/post2015/ transformingourworld/publication. Accessed 30 July 2020.

17. The World Bank. World Bank Country and Lending Groups Country Classification 2020 https://datahelpdesk.worldbank.org/knowledgebase/artic les/906519-world-bank-country-and-lending-groups. Accessed 24 Nov 2020

18. Cottingham J, Kismodi E, Hilber AM, Lincetto O, Stahlhofer M, Gruskin S. Using human rights for sexual and reproductive health: improving legal and regulatory frameworks. Bull World Health Organ. 2010;88(7):551-5.

19. Germain A. Editor meeting human rights norms for the quality of sexual and reproductive health information and services: Discussion paper. International Conference on Human Rights; 2013. Noordwijk, The Netherlands: United Nations Population Fund; 2013.
20. Sundari Ravindran TK, Govender V. Sexual and reproductive health services in universal health coverage: a review of recent evidence from low- and middle-income countries. Sex. Reprod Health Matters. 2020:28(2):1-22.

21. Filler T, Jameel B, Gagliardi AR. Barriers and facilitators of patient centered care for immigrant and refugee women: a scoping review. BMC Public Health. 2020;20(1):1013.

22. Vermeir P, Vandijck D, Degroote S, Peleman R, Verhaeghe R, Mortier E, et al. Communication in healthcare: a narrative review of the literature and practical recommendations. Int J Clin Pract. 2015;69(11):1257-67.

23. Williams K, Warren C, Askew I. Planning and implementing an essentia package of sexual and reproductive health services. Geneva: United Nations Populations Fund. 2010. https://www.unfpa.org/sites/default/ files/resource-pdf/Essential_Package_Integration.pdf. Accessed 2 Oct 2020

24. World Health Organisation. Primary health care on the road to universal health coverage - monitoring report. Geneva; 2019. https://www.who. int/publications/i/item/9789240029040. Accessed 24 Nov 2020.

25. Casey SE. Evaluations of reproductive health programs in humanitarian settings: a systematic review. Confl Heal. 2015;9(1):S1.

26. Amiri M, El-Mowafi IM, Chahien T, Yousef H, Kobeissi LH. An overview of the sexual and reproductive health status and service delivery among Syrian refugees in Jordan, nine years since the crisis: a systematic literature review. Reprod Health. 2020;17(1):166.

27. Foster AM, Evans DP, Garcia M, Knaster S, Krause S, McGinn T, et al. The 2018 inter-agency field manual on reproductive health in humanitarian settings: revising the global standards. Reprod Health Matters. 2017;25(51):18-24.

28. Hadgkiss EJ, Renzaho AM. The physical health status, service utilisation and barriers to accessing care for asylum seekers residing in the community: a systematic review of the literature. Aust Health Rev. 2014;38(2):142-59.

29. Sarria-Santamera A, Hijas-Gomez Al, Carmona R, Gimeno-Feliu LA. A systematic review of the use of health services by immigrants and native populations. Public Health Rev. 2016;37:28

30. Riggs E, Davis E, Gibbs L, Block K, Szwarc J, Casey S, et al. Accessing maternal and child health services in Melbourne, Australia: reflections from refugee families and service providers. BMC Health Serv Res. 2012;12:117.

31. Yelland J, Riggs E, Szwarc J, Casey S, Duell-Piening P, Chesters D, et al. Compromised communication: a qualitative study exploring afghan families and health professionals' experience of interpreting support in Australian maternity care. BMJ Qual Saf. 2016:25(4):e1.

32. Owens C, Dandy J, Hancock P. Perceptions of pregnancy experiences when using a community-based antenatal service: a qualitative study of refugee and migrant women in Perth, Western Australia. Women Birth. 2016;29(2):128-37.

33. O'Mahony J, Donnelly T. Immigrant and refugee women's postpartum depression help-seeking experiences and access to care: a review and analysis of the literature. J Psychiatr Ment Health Nurs. 2010;17(10):917-28.

34. Khanlou N, Haque N, Skinner A, Mantini A, Kurtz LC. Scoping review on maternal health among immigrant and refugee women in Canada: prenatal, intrapartum, and postnatal care. J Pregnancy. 2017:2017:8783294.

35. Heslehurst N, Brown H, Pemu A, Coleman H, Rankin J. Perinatal health outcomes and care among asylum seekers and refugees: a systematic review of systematic reviews. BMC Med. 2018;16(1):89.

36. Cheng $\mathrm{IH}$, Drillich A, Schattner P. Refugee experiences of general practice in countries of resettlement: a literature review. Br J Gen Pract. 2015;65(632):E171-E6.

37. Bhatia R, Wallace P. Experiences of refugees and asylum seekers in general practice: a qualitative study. BMC Fam Pract. 2007;8:48.

38. Brandenberger J, Tylleskar T, Sontag K, Peterhans B, Ritz N. A systematic literature review of reported challenges in health care delivery to migrants and refugees in high-income countries - the 3C model. BMC Public Health. 2019;19:755.

39. Mengesha ZB, Perz J, Dune T, Ussher J. Refugee and migrant women's engagement with sexual and reproductive health care in Australia: a socio-ecological analysis of health care professional perspectives. PLoS One. 2017;12(7):e0181421

40. Robertshaw L, Dhesi S, Jones LL. Challenges and facilitators for health professionals providing primary healthcare for refugees and asylum 
seekers in high-income countries: a systematic review and thematic synthesis of qualitative research. BMJ Open. 2017;7(8):e015981.

41. Mengesha ZB, Perz J, Dune T, Ussher J. Preparedness of health care professionals for delivering sexual and reproductive health care to refugee and migrant women: a mixed methods study. Int J Environ Res Public Health. 2018;15:174.

42. Moher D, Liberati A, Tetzlaff J, Altman DG, Group P. Preferred reporting items for systematic reviews and meta-analyses: the PRISMA statement. J Clin Epidemiol. 2009;62(10):1006-12.

43. Cooke A, Smith D, Booth A. Beyond PICO: the SPIDER tool for qualitative evidence synthesis. Qual Health Res. 2012;22(10):1435-43.

44. Covidence. Better systematic review management (2020) https://www. covidence.org/. Accessed 20 Oct 2020.

45. Kmet LM, Lee RC, Cook LS. Standard quality assessment criteria for evaluating primary research papers from a variety of fields. Edmonton, Canada: Alberta Heritage Foundation for Medical Research; 2004.

46. Popay JRH, Sowden A, Petticrew M, Arai L, Rodger M, Britten N, et al. Guidance on the conduct of narrative synthesis in systematic reviews. A Product from the ESRC Methods Programme. Lancaster: Lancaster University; 2006.

47. Morrison V. Contraceptive need among Cambodian refugees in Khao Phlu camp. Int Fam Plan Perspect. 2000;26(4):188-92.

48. Gurnah K, Khoshnood K, Bradley E, Yuan C. Lost in translation: reproductive health care experiences of Somali bantu women in Hartford, Connecticut. J Midwifery Women's Health. 2011;56(4):340-6.

49. Cherri Z, Gil Cuesta J, Rodriguez-Llanes JM, Guha-Sapir D. Early marriage and barriers to contraception among Syrian refugee women in Lebanon: a qualitative study. Int J Environ Res Public Health. 2017;14(8):25.

50. Kabakian-Khasholian T, Mourtada R, Bashour H, El Kak F, Zurayk H. Perspectives of displaced Syrian women and service providers on fertility behaviour and available services in west Bekaa, Lebanon. Reprod Health Matters. 2017;25(Supplement 1):S75-86.

51. Tanabe M, Myers A, Bhandari P, Cornier N, Doraiswamy S, Krause S Family planning in refugee settings: findings and actions from a multicountry study. Conflict and Health. 2017;11:9.

52. West L, Isotta-Day H, Ba-Break M, Morgan R. Factors in use of family planning services by Syrian women in a refugee camp in Jordan. J Fam Plann Reprod Health Care. 2017;43(2):96-102.

53. Agbemenu K, Volpe EM, Dyer E. Reproductive health decision-making among US-dwelling Somali bantu refugee women: a qualitative study. J Clin Nurs. 2018;27(17-18):3355-62.

54. Gebreyesus T, Gottlieb N, Sultan Z, Ghebrezghiabher HM, Tol W, Winch $\mathrm{PJ}$, et al. Barriers to contraceptive careseeking: the experience of Eritrean asylum-seeking women in Israel. Ethn Health. 2020;25(2):255-72.

55. Royer PA, Olson LM, Jackson B, Weber LS, Gawron L, Sanders JN, et al. "In Africa, there was no family planning. Every year you just give birth": family planning knowledge, attitudes, and practices among Somali and Congolese refugee women after resettlement to the United States. Qual Health Res. 2020;30(3):391-408.

56. Zhang Y, McCoy EE, Scego R, Phillips W, Godfrey E. A qualitative exploration of Somali refugee Women's experiences with family planning in the U.S. J Immigr Minor Health. 2020;22(1):66-73.

57. Haworth RJ, Margalit R, Ross C, Nepal T, Soliman AS. Knowledge, attitudes, and practices for cervical cancer screening among the Bhutanese refugee community in Omaha, Nebraska. J Community Health. 2014;39(5):872-8

58. Kim K, Kim S, Chung Y. A qualitative study exploring factors associated with pap test use among north Korean refugees. Health Care Women Int. 2017;38(10):1115-29.

59. Lor B, Ornelas IJ, Magarati M, Do HH, Zhang Y, Jackson JC, et al. We should know ourselves: Burmese and Bhutanese refugee Women's perspectives on cervical Cancer screening. J Health Care Poor Underserved. 2018;29(3):881-97.

60. Allen EM, Lee HY, Pratt R, Vang H, Desai JR, Dube A, et al. Facilitators and barriers of cervical Cancer screening and human papilloma virus vaccination among Somali refugee women in the United States: a qualitative analysis. J Transcult Nurs. 2019;30(1):55-63.

61. Ross Perfetti A, Abboud S, Behme M, Barg FK. Understanding wellness and barriers to care among Iraqi refugee women in the United States. Health Soc Care Commun. 2019;27(6):1430-7.
62. Babatunde-Sowole OO, Power T, Davidson PM, DiGiacomo M, Jackson D. Health screening and preventative health care in refugee women: a qualitative analysis. Contemp Nurse. 2020:1-30.

63. Saadi A, Bond BE, Percac-Lima S. Bosnian, Iraqi, and Somali refugee women speak: a comparative qualitative study of refugee health beliefs on preventive health and breast Cancer screening. Womens Health Issues. 2015;25(5):501-8.

64. Parajuli J, Horey D, Avgoulas M-I. Access to breast cancer screening -- perception, and perceived barriers among older Bhutanese refugee women resettled in Australia: a qualitative study. Aust J Cancer Nurs. 2019;20(1):14-8.

65. Raheel H, Karim MS, Saleem S, Bharwani S. Knowledge, Attitudes and practices of contraception among afghan refugee women in Pakistan: a cross-sectional study. PLoS One. 2012;7(11).

66. Kisindja RM, Kimona C, Etoy M, Dorme F, Benfield N. Family planning knowledge and use among women in camps for internally displaced people in the Democratic Republic of the Congo. Int J Gynaecol Obstet. 2017:138(3):256-60

67. Raben LAD, Muijsenbergh METCvd. Inequity in contraceptive care between refugees and other migrant women?: a retrospective study in Dutch general practice. Fam Pract. 2018;35(4):468-74.

68. Pierce $\mathrm{H}$. Reproductive health care utilization among refugees in Jordan: Provisional support and domestic violence. Women Health. 2019;15:1-10.

69. Barnes DM, Harrison CL. Refugee women's reproductive health in early resettlement. J Obstet Gynecol Neonatal Nurs. 2004;33(6):723-8.

70. Redwood-Campbell L, Thind H, Howard M, Koteles J, Fowler N, Kaczorowski J. Understanding the health of refugee women in host countries: lessons from the Kosovar re-settlement in Canada. Prehospital Disaster Med. 2008;23(4):322-7.

71. Lofters AK, Moineddin R, Hwang SW, Glazier RH. Predictors of low cervical cancer screening among immigrant women in Ontario, Canada. BMC Womens Health. 2011;11(1):20.

72. Odunukan OW, Abdulai RM, Hagi Salaad MF, Lahr BD, Flynn PM, Wieland ML. Provider and interpreter preferences among Somali women in a primary care setting. J Prim Care Community Health. 2015;6(2):105-10.

73. Banke-Thomas A, Agbemenu K, Johnson-Agbakwu C. Factors associated with access to maternal and reproductive health care among Somali refugee women resettled in Ohio, United States: a cross-sectional survey. J Immigr Minor Health. 2019;21(5):946-53.

74. Zhang Y, Ornelas IJ, Do HH, Magarati M, Jackson JC, Taylor VM. Provider perspectives on promoting cervical Cancer screening among refugee women. J Community Health. 2017;42(3):583-90.

75. Finfgeld-Connett D. Generalizability and transferability of meta-synthesis research findings. Oxford, UK. 2010. 246-254.

76. Finlay L, Gough B. ProQuest. Reflexivity : a practical guide for researchers in health and social sciences. 1st ed. Malden: Blackwell Science; 2003.

77. Pranee L. Focus group methodology and sensitive topics and vulnerable groups. London: SAGE Publications Ltd; 2011. p. 107.

78. Merry L, Clausen C, Gagnon AJ, Carnevale F, Jeannotte J, Saucier JF, et al. Improving qualitative interviews with newly arrived migrant women. Qual Health Res. 2011;21(7):976-86.

79. Wangdahl J, Westerling R, Lytsy P, Martensson L. Perspectives on health examination for asylum seekers in relation to health literacy - focus group discussions with Arabic and Somali speaking participants. BMC Health Serv Res. 2019;19(1):676.

80. Bowling A. Mode of questionnaire administration can have serious effects on data quality. J Public Health (Oxf). 2005;27(3):281-91.

81. Floyd A, Sakellariou D. Healthcare access for refugee women with limited literacy: layers of disadvantage. Int J Equity Health. 2017;16(1).

82. Bischoff A, Bovier PA, Isah R, Francoise G, Ariel E, Louis L. Language barriers between nurses and asylum seekers: their impact on symptom reporting and referral. Soc Sci Med. 2003;57(3):503-12.

83. Schyve PM. Language differences as a barrier to quality and safety in health care: the joint commission perspective. J Gen Intern Med. 2007;22(Suppl 2):360-1.

84. Degni F, Suominen S, Essen B, El Ansari W, Vehvilainen-Julkunen K. Communication and cultural issues in providing reproductive health care to immigrant women: health care providers' experiences in meeting the needs of [corrected] Somali women living in Finland. J Immigr Minor Health. 2012;14(2):330-43. 
85. Mengesha ZB, Perz J, Dune T, Ussher J. Talking about sexual and reproductive health through interpreters: the experiences of health care professionals consulting refugee and migrant women. Sexual Reprod Healthcare. 2018;16:199-205.

86. The University of Sydney. What is cultural competence? Sydney: National Centre for Cultural Competence; 2021 https://www.sydney.edu.au/nccc/ about-us/what-is-cultural-competence.html. Accessed 29 July 2021.

87. Saha S, Beach MC, Cooper LA. Patient centeredness, cultural competence and healthcare quality. J Natl Med Assoc. 2008;100(11):1275-85.

88. Rade DA, Crawford G, Lobo R, Gray C, Brown G. Sexual health help-seeking behavior among migrants from sub-Saharan Africa and South East Asia living in high income countries: a systematic review. Int J Environ Res Public Health. 2018;15(7):22.

89. Bertakis KD, Azari R. Patient-centered care: the influence of patient and resident physician gender and gender concordance in primary care. J Women's Health (Larchmt). 2012;21 (3):326-33.

90. Metusela C, Ussher J, Perz J, Hawkey A, Morrow M, Narchal R, et al. "In my culture, we Don't know anything about that": sexual and reproductive health of migrant and refugee women. Int J Behav Med. 2017;24(6):836-45.

91. Carroll J, Epstein R, Fiscella K, Gipson T, Volpe E, Jean-Pierre P, et al. Caring for Somali women: implications for clinician-patient communication. Patient Educ Couns. 2007;66(3):337-45.

92. Anaman JA, Correa-Velez I, King J. A survey of cervical screening among refugee and non-refugee African immigrant women in Brisbane, Australia Health Promotion. J Aust. 2016;28(3):217-24.

93. Murray L, Elmer S, Elkhair J. Perceived barriers to managing medications and solutions to barriers suggested by Bhutanese former refugees and service providers. J Transcult Nurs. 2018;29(6):570-7.

94. Truong M, Paradies Y, Priest N. Interventions to improve cultural competency in healthcare: a systematic review of reviews. BMC Health Serv Res. 2014;14:99.

95. Betancourt JR, Green AR, Carrillo JE, Ananeh-Firempong O. Defining cultural competence: a practical framework for addressing racial/ethnic disparities in health and health care. Public Health Rep. 2003;1 18(4):293-302.

96. Zeh P, Sandhu HK, Cannaby AM, Sturt JA. The impact of culturally competent diabetes care interventions for improving diabetes-related outcomes in ethnic minority groups: a systematic review. Diabet Med. 2012;29(10):1237-52.

97. Handtke O, Schilgen B, Mösko M. Culturally competent healthcare - a scoping review of strategies implemented in healthcare organizations and a model of culturally competent healthcare provision. PLoS One. 2019;14(7):e0219971.

98. Shepherd SM, Willis-Esqueda C, Newton D, Sivasubramaniam D, Paradies Y. The challenge of cultural competence in the workplace: perspectives of healthcare providers. BMC Health Serv Res. 2019;19(1):135.

\section{Publisher's Note}

Springer Nature remains neutral with regard to jurisdictional claims in published maps and institutional affiliations.

Ready to submit your research? Choose BMC and benefit from:

- fast, convenient online submission

- thorough peer review by experienced researchers in your field

- rapid publication on acceptance

- support for research data, including large and complex data types

- gold Open Access which fosters wider collaboration and increased citations

- maximum visibility for your research: over 100M website views per year

At BMC, research is always in progress.

Learn more biomedcentral.com/submissions 